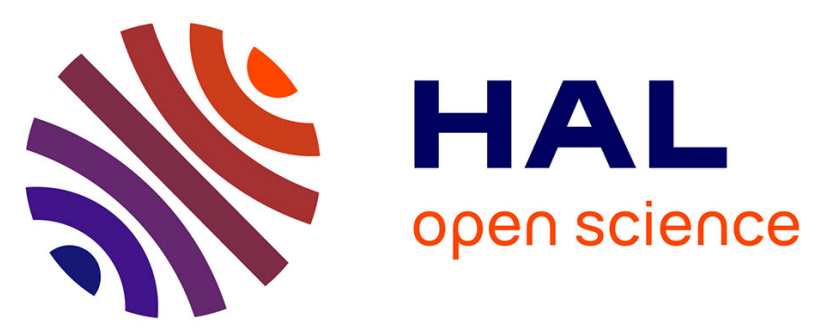

\title{
Monocore vs multicore magnetic iron oxide nanoparticles: uptake by glioblastoma cells and efficiency for magnetic hyperthermia
}

Gauvin Hemery, Coralie Genevois, Franck Couillaud, Sabrina Lacomme, Etienne Gontier, Emmanuel Ibarboure, Sébastien Lecommandoux, Elisabeth Garanger, Olivier Sandre

\section{To cite this version:}

Gauvin Hemery, Coralie Genevois, Franck Couillaud, Sabrina Lacomme, Etienne Gontier, et al.. Monocore vs multicore magnetic iron oxide nanoparticles: uptake by glioblastoma cells and efficiency for magnetic hyperthermia. Molecular Systems Design \& Engineering, 2017, 2 (5), pp.629-639. 10.1039/C7ME00061H . hal-01628901v2

\section{HAL Id: hal-01628901 \\ https://hal.science/hal-01628901v2}

Submitted on 4 Dec 2017

HAL is a multi-disciplinary open access archive for the deposit and dissemination of scientific research documents, whether they are published or not. The documents may come from teaching and research institutions in France or abroad, or from public or private research centers.
L'archive ouverte pluridisciplinaire HAL, est destinée au dépôt et à la diffusion de documents scientifiques de niveau recherche, publiés ou non, émanant des établissements d'enseignement et de recherche français ou étrangers, des laboratoires publics ou privés. 


\title{
Monocore vs multicore magnetic iron oxide nanoparticles: uptake by glioblastoma cells and efficiency for magnetic hyperthermia
}

Received 21st July 2017,

Accepted 3rd November 2017

DOI: $10.1039 / \mathrm{c} 7 \mathrm{me} 00061 \mathrm{~h}$

rsc.li/molecular-engineering

\author{
Gauvin Hemery ${ }^{a}$, Coralie Genevois ${ }^{b}$, Franck Couillaud ${ }^{b}$, Sabrina Lacomme ${ }^{c}$, Etienne \\ Gontier $^{c}$, Emmanuel Ibarboure ${ }^{\mathrm{a}}$, Sébastien Lecommandoux ${ }^{\mathrm{a}}$, Elisabeth Garanger ${ }^{\mathrm{a}^{*}}$, and \\ Olivier Sandre $\mathrm{a}^{\mathrm{a}^{*}}$
}

PEGylated magnetic iron oxide nanoparticles (IONPS) were synthesised with the aim to provide proof of concept results of remote cancer cell killing by magnetic fluid hyperthermia. The IONPs were produced by
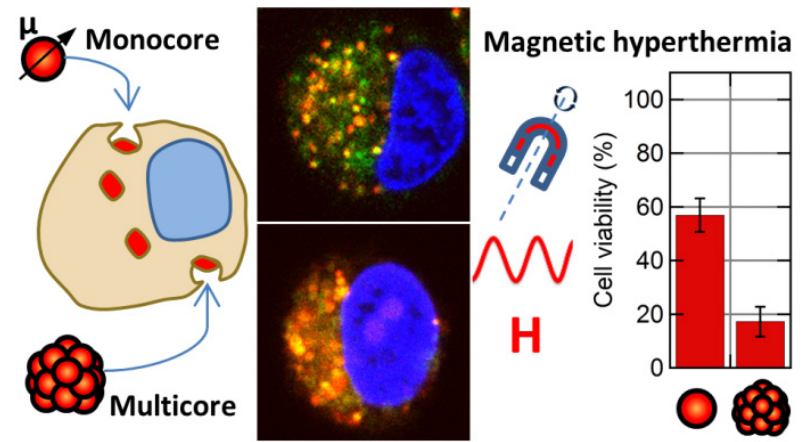

the polyol synthetic route also called "forced hydrolysis pathway" yielding highly superparamagnetic, readilydispersible, and biocompatible IONPs. As shown previously, adjusting parameters of the reaction led to either monocore or multicore IONPS, with on-demand morphology and magnetic properties. Polyethylene glycol (PEG) was grafted onto the nanoparticles in a single final step, using a phosphonic acid-terminated

PEG synthesised separately, a strategy named "convergent". The magnetic properties of the IONPs were preserved in physiological media thanks to this biocompatible shell. The interaction of the PEGylated IONPs with a glioblastoma cell line was studied, from the stability of IONPs in appropriate cell culture medium to the remotely magnetically triggered cell death. Cellular internalisation of the IONPs was studied, along with their fate after application of an alternating magnetic field (AMF). This investigation highlights the superior efficiency of multicore (nanoflowers) vs monocore (nanospheres) IONPs for magnetic hyperthermia, leading to $80 \%$ cancer cells death in medically translatable conditions.

\section{Introduction}

Cancer is a major cause of death in developed countries, and is the second cause of death in the US and Europe. ${ }^{1}$ Among the different types and locations of cancer, malignant brain tumours show lower incidence compared to more common breast, prostate or liver cancers, with an annual global agestandardised incidence of 2.6 and 3.7 per 100,000 individuals, for females and males respectively. ${ }^{2}$ However, brain tumours of high grade (glioblastoma) are aggressive and have very poor prognosis. They are exceedingly complicated to treat due to their deep implantation in the cranial cavity, limiting the ease of treatment, and to the vital role of the brain limiting tumour resection by surgery. Patients suffering from glioblastoma have a median survival of 14 months, ${ }^{3}$ with survival chance depending on various parameters, such as size and location of the tumour, patient age, and administrated treatment. ${ }^{4}$

\footnotetext{
a. Laboratoire de Chimie des Polymères Organiques (LCPO) UMR 5629 CNRS / Univ. Bordeaux / Bordeaux-INP, ENSCBP 16 avenue Pey Berland, 33607 Pessac, France

${ }^{b .}$ Imagerie moléculaire et thérapies innovantes en oncologie (IMOTION) EA 7435Univ. Bordeaux, 33706 Bordeaux, France

Bordeaux Imaging Center (BIC) UMS 3420 CNRS / Univ. Bordeaux UBS - US4 INSERM-F-33000 Bordeaux, France

*Corresponding Authors: olivier.sandre@enscbp.fr, elisabeth.garanger@enscbp.fr Electronic Supplementary Information (ESI) available: TEM micrographs and size histograms; temperature profiles; synthesis schemes; thin layer chromatography analysis; ${ }^{1} \mathrm{H}$ NMR spectrum; absorbance and fluorescence spectra; photographs of MNP suspensions; supplementary images of cells and organelles (bright field micrographs, TEM micrographs, confocal micrographs and co-localization study).
}

Standard existing solutions to treat cancers by resection when possible, radiotherapy and chemotherapy have to be combined into a multi-modal treatment line yet with generally poor prognostis, ${ }^{4}$ marginal benefits and only few survival months. ${ }^{3}$ In search for a more efficient cure, magnetic fluid hyperthermia (MFH) coupled with conventional radiotherapy proved to be a promising alternative, well-tolerated by the patients, with little to no side effects. ${ }^{5}$ In a phase 3 clinical trial, intra-tumour MFH combined with X-rays enabled to prolong the median survival time from 14.6 to 23.2 months, $^{6}$ and is now authorised in clinics. In parallel, different pre-clinical models were developed to test the conditions of $\mathrm{MFH}$ application in vitro on different cell lines or in vivo on small animals (mostly rodents). Emphasis was placed in particular on the type of magnetic nanoparticles used to generate heat and on the characteristics of the alternating magnetic field (AMF). ${ }^{7}$ Magnetic iron oxide nanoparticles (IONPs) are in this sense promising internal heating agents for magnetic hyperthermia, due to their inherent biocompatibility and because they can reach sufficiently high values of specific absorption rates (SAR) to elevate temperature up to $51.2{ }^{\circ} \mathrm{C}$ in glioblastomas by intratumour injection. ${ }^{6}$ Among the different synthesis pathways yielding IONPs (alkaline co-precipitation, hydrothermal treatment, thermal decomposition....), ${ }^{8}$ we chose in this study the polyol route introduced by Caruntu et al. ${ }^{9}$ as this synthesis is robust, up-scalable and enables producing either monocore or multicore IONPs. Also called "nanoflowers", the latter are among the synthetic IONPs with the highest reported SAR 
values, of $\sim 1 \mathrm{~kW} \cdot \mathrm{g}^{-1}$ or more, ${ }^{10-12}$ yet at AMF conditions that moderately exceed the "Brezovich criterion" on the product of AMF frequency and intensity, i.e. by a factor $\sim 10$ only ( $\left.f \times H<5 \cdot 10^{9} \mathrm{~A} \cdot \mathrm{m}^{-1} \cdot \mathrm{s}^{-1}\right)$, as proposed by Dutz and Hergt. ${ }^{13}$ As reported in literature, ${ }^{14-16}$ higher specific heating rates of multicore IONPs as compared to single core IONPs are ascribed to "spin glass" dynamics of the magnetic moments within a cluster, strongly correlated by the exchange interaction. This collective behaviour enhances the magnetic susceptibility, i.e. magnetic response at low magnetic field strength (DC or $A C$ ), once the applied field overcomes the intrinsic anisotropy field. The present study aims at comparing the efficacy of these two morphologies (monocore vs multicore) for treating human glioblastoma cells in vitro. The surfaces of these two types of IONPs were functionalised with a dense polymer brush of poly(ethylene glycol) (PEG) as a stabiliser for bringing longer blood circulation lifetime in vivo. The "convergent" grafting strategy uses a phosphonic acid group at one end of the chains, a ligand known to provide a strong chelating effect at the surface of IONPs. Phosphonates and bis-phosphonates were already used as chain end-groups for IONP pegylation. ${ }^{17}$ In previous reports studying stealth IONPs in vitro or in vivo, phosphonic acid anchors were rather grafted along the polymer backbone, either in a block structure with $\mathrm{PEG}^{18,19}$ or as a statistical copolymer with PEG sidechains. ${ }^{20}$ Other types of anchoring moieties are also used for IONP pegylation, like nitrodopamine ${ }^{21}$ or silanes ${ }^{22,23}$. In the present study, the near infrared (NIR) fluorescent dye DY700 that is stable under in vitro conditions and has low cytotoxicity ${ }^{24}$ was also grafted using the phosphonate pre-functionalisation strategy in order to easily track the IONPs incubated with cells. A U87 human glioblastoma cell line, genetically modified to overexpress the bioluminescent reporter gene firefly luciferase (Fluc), was used to provide a convenient way to monitor the time course of cell viability by bioluminescence imaging (BLI) and to quantify the IONPs' performances in terms of magnetically-induced toxicity. ${ }^{25,26}$ The internalisation pathway was studied both by transmission electron microscopy (TEM) of cell microtomes and by confocal laser scanning microscopy (CLSM) of living cells, evidencing that the IONPS were internalised inside intracellular compartments, more precisely in lysosomes. The quantities of IONPs internalised inside the cells for several conditions of incubation were determined by flow cytometry and fluorescence imaging, showing good correlation with IONP concentration during incubation. Their efficiency to induce U87 glioblastoma cell death by MFH was assessed by BLI measurements, as luciferase expression is ATP-dependent and thus serves as a quantitative and direct read-out of cell viability. ${ }^{27}$ We evidenced noticeable differences between monocore and multicore IONPs, regarding their internalisation and the magnetically-induced cytotoxicity effects. a)

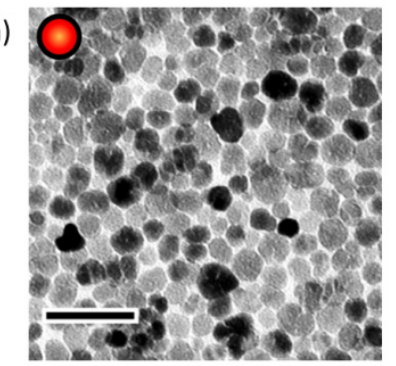

b)

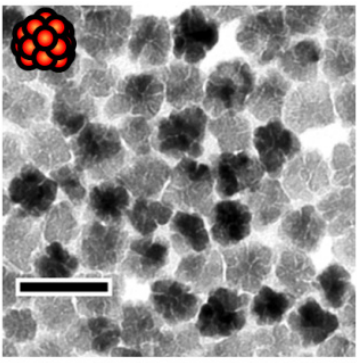

c)

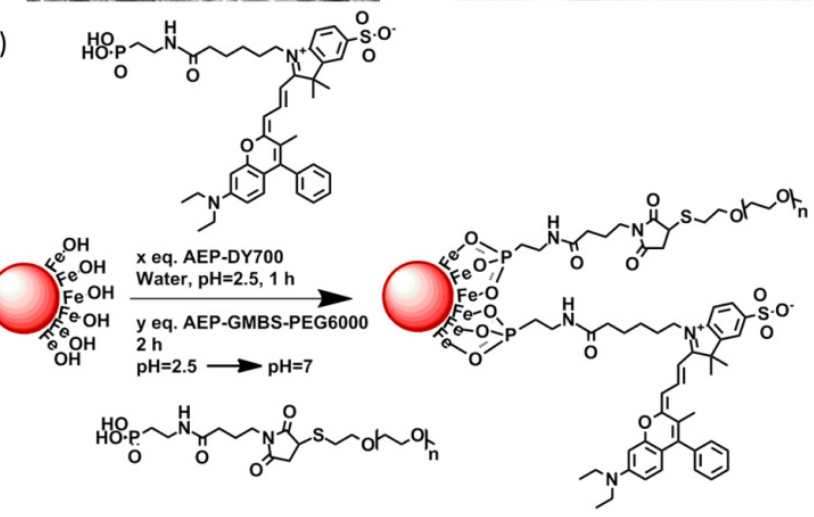

Fig. 1. TEM micrographs of a) monocore and b) multicore IONPs of diameters respectively $14.5 \pm 3.4$ and $29.1 \pm 4.4 \mathrm{~nm}$ as measured on histograms (Fig. S1 and Fig. S2). The scale bar length is $50 \mathrm{~nm}$. c) Grafting of the fluorescent probe DY700 and PEG onto the surface of an IONP in a simple one-step "convergent strategy" after their prior modification by a phosphonate anchor, contrary to multiple successive grafting steps.

\section{Results and discussion}

Monocore and multicore IONPs were synthesised by the forced hydrolysis route in a mixture of polyol and poly(hydroxy)amine with controlled addition of water during the reaction, as previously described elsewhere. ${ }^{12}$ The batches of monocore and multicore IONPs selected for this study presented specific absorption rates (SAR) of 134 and $265 \mathrm{~W} \cdot \mathrm{g}^{-1}$, respectively (Fig. S3), in AMF conditions $\left(755 \mathrm{kHz}, 10 \mathrm{kA} \cdot \mathrm{m}^{-1}\right.$ ) which, due to the use of a different generator, were not the same as the ones used later on for the biological experiments $\left(473 \mathrm{kHz}, 12 \mathrm{kA} \cdot \mathrm{m}^{-1}\right)$. Their surface was chemically modified by grafting $6,000 \mathrm{MW}$ PEG chains in order to provide steric repulsion and ensure colloidal stability in physiological media. The PEG was primarily modified at one end by introducing a phosphonic acid anchor group, which was subsequently used to tether the chains at the surface of IONPs in a single reaction step (Fig. 1). The number of PEG chains per IONP was adjusted to form a dense repulsive brush. A NIR fluorescent probe (DY700-NHS ester, Dyomics $\mathrm{GmbH}$, Jena) was simultaneously grafted at the IONP surface using a similar strategy. The onestep grafting of the dye and the PEG chains was thought more efficient than a multistep grafting of individual components (i.e. phosphonate anchor, cross-linker, PEG or dye) on the surface of the IONPs. Individual components of the molecules were thus conjugated separately to access a phosphonic acidcontaining version of DY700 (AEP-DY700) (Fig. S6) and PEG (AEP-GMBS-PEG) (Fig. S4) thereby enabling their one pot single step grafting onto the IONP surface. Synthetic intermediates were isolated and analysed using common techniques such as 
${ }^{1}$ H NMR (Fig. S5) or thin layer chromatography (TLC) (Fig. S7): Such chemical characterisation would not have been feasible if the molecules were successively grafted onto the magnetic cores. The yield of DY700-AEP coupling reaction was evaluated at $80 \%$ for by TLC (Fig. S8), the same value being found also for AEP-GMBS-PEG by integrating the protons on the ${ }^{1} \mathrm{H} N M R$ spectrum. The single step grafting strategy has also the major advantage of taking place in aqueous weakly acidic conditions, wherein IONPs are fully stable and well-dispersed. This insures the modification of the whole surface area, as compared to the difficult homogeneous coating of clustered nanoparticles or aggregates. The IONPs were stirred with AEP-DY700 for $1 \mathrm{~h}$ and then with AEP-GMBS-PEG in acidic water $(\mathrm{pH}=2.5)$ for $2 \mathrm{~h}$, before neutralising the $\mathrm{pH}$ with Tris $50 \mathrm{mM}$ and purifying IONPs by centrifugation-redispersion cycles (Fig. S9). The ratio of PEG to IONP was calculated to form a dense PEG layer. In order to obtain a grafting density sufficient to reach the "brush regime" so that the tethered chains were neither too far from each other ("mushroom regime") nor too extended, we used the criterion established by Brittain and Minko ${ }^{28}$ comparing the chain-to-chain distance $D$ between the grafting points to the gyration radius $R_{\mathrm{G}}$ of the free chains in solution through the reduced grafting density $\Sigma=\pi R_{\mathrm{G}}^{2} / D^{2}$. In this dense brush regime defined by $\Sigma>5,{ }^{28}$ the IONPs are stabilised by maximal steric repulsions. The surface modification of the IONPS was assessed by dynamic light scattering (DLS), measuring the hydrodynamic diameters and polydispersity index (PDI) of the IONPs in suspension: For bare nanoparticles (at $\mathrm{pH}=2.5$ in dilute $\mathrm{HNO}_{3}$ ), the $Z$-average diameter is $21.3 \mathrm{~nm}$ for the monocore IONPS (PDI=0.16) and $37.6 \mathrm{~nm}$ for the multicores ( $P D I=0.19$ ), which increases to $47.5 \mathrm{~nm}$ ( $P D I=0.37)$ and $57.8 \mathrm{~nm}(\mathrm{PDI}=0.33)$ respectively after coating $(50 \mathrm{mM}$ Tris at $\mathrm{pH} 7$ ) due to the formation of an organic shell. Efficient PEG coating was also evidenced by photographs of the resulting stable suspensions in aqueous media at neutral pH (Fig. S11).

The NIR fluorescent probe AEP-DY700 was coupled directly onto the surface of IONPs resulting in a very likely shielding of the dye by the PEG layer. The proximity of the fluorescent DY700 with the surface of the semi-conducting iron oxide was expected to lead to partial quenching of the fluorescence signal. This phenomenon may occur through two separate mechanisms: i) by IONP/fluorophore interaction ${ }^{29}$ and/or ii) by fluorophore/fluorophore self-quenching due to a high local concentration of dye. The amount of dye to graft was therefore limited to $1 \% \mathrm{w} / \mathrm{w}$, to guaranty a sufficient fluorescence signal for detection as well as to avoid covering the IONP surface with a hydrophobic molecule. Using a spacer to increase the distance between the IONP surface and the dye as well as the distance between fluorophores was another option. However, we considered that the DY700 conjugation close to the IONP surface would prevent undesirable hydrophobic interactions with the environment (biological fluids, cells, etc....). The DY700 characteristic wavelengths are respectively $\lambda_{\text {exc }}=650 \mathrm{~nm}$ for excitation and $\lambda_{\text {em }}=700 \mathrm{~nm}$ for emission (Fig. S9-S10). These values are in the NIR region of the electromagnetic spectrum, a range of minimum absorption of biological fluids and tissues, also far from the shorter wavelength radiations that are strongly absorbed by IONPs.

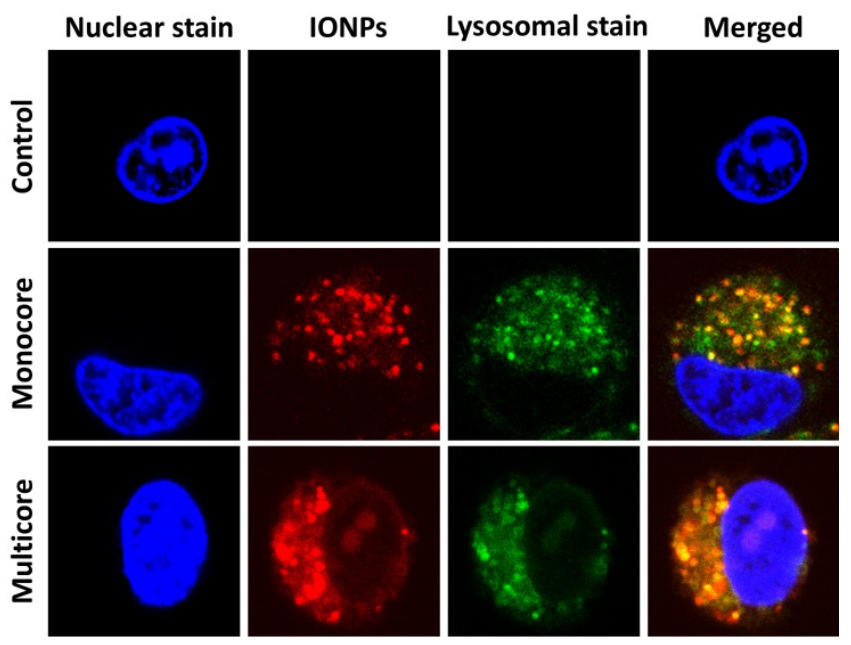

Fig. 2. Intracellular distribution of IONPs in U87 glioblastoma cells. Cells were incubated with IONPs conjugated to DY700 (red) for $24 \mathrm{~h}$ at $100 \mu \mathrm{g} \cdot \mathrm{mL}^{-1}$. They were visualised by fluorescence confocal microscopy at $63 \times$ magnification. The nucleus (blue) was stained with Hoechst $33342\left(2 \mu \mathrm{g} \cdot \mathrm{mL}^{-1}\right)$, the lysosomes (green) with Lysotracker ${ }^{\mathrm{TM}}$ green (100 nM). Red-green dye co-localization was quantified (Fig. S24)

The interactions between cells and IONPS were investigated, using a U87 human glioblastoma cell line, genetically modified to overexpress a bioluminescent reporter gene (Fluc) under the transcriptional control of constitutive CMV promoter. The luciferase expressed by cells is an enzyme which catalyses D-luciferin oxidation to produce photons. Emitted light is correlated with the dioxygen- and ATPdependant activity of luciferase which is itself correlated with cell viability $\left(\mathrm{O}_{2}\right.$ and ATP content) and cell numbers (luciferase amount) in the samples. ${ }^{27}$ Following addition of D-luciferin in the culture medium, light emission was monitored noninvasively, by bioluminescence imaging (BLI). This property was further used as a viability assay when evaluating the effect of IONPs on cells under magnetic field hyperthermia. U87 cells were incubated with IONPs for $24 \mathrm{~h}$. The blue fluorescence signal of the Hoechst dye was specifically located in the nuclei, revealing the position of the cells in the sample (Fig. 2). A strong red fluorescent signal ascribed to DY700 was detected, evidencing the presence of the IONPs. Images captured at different confocal section planes assessed that the IONPs were located inside the cytoplasm and particularly in the vicinity of the nucleus. The aspect and range of sizes of fluorescent spots suggested an endocytosis internalisation pathway, and most likely corresponds to lysosomes. Therefore the green fluorescent Lysotracker ${ }^{\mathrm{TM}}$ dye was used to confirm this hypothesis. The green fluorescent signal was observed inside cells when incubated with the IONPs, while no lysosomes were detected for non-treated control cells. The red fluorescence spots of IONPs were exclusively co-localised with the green fluorescent signal of lysosomes, resulting in yellow fluorescent spots. The same image analysis tool used by Connord et al. to prove the utmost important role played by lysosomes in intracellular $\mathrm{MFH}^{30}$ also led here to high dye co-localization 
coefficients (Fig. S24). This finding further suggests that the degradative enzymes contained within the lysosomes were unable to alter the fluorescence signal of the DY700 NIR dyes. a)

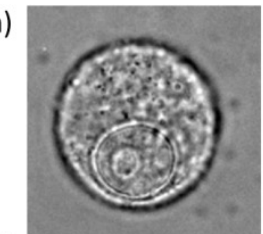

d)

e)
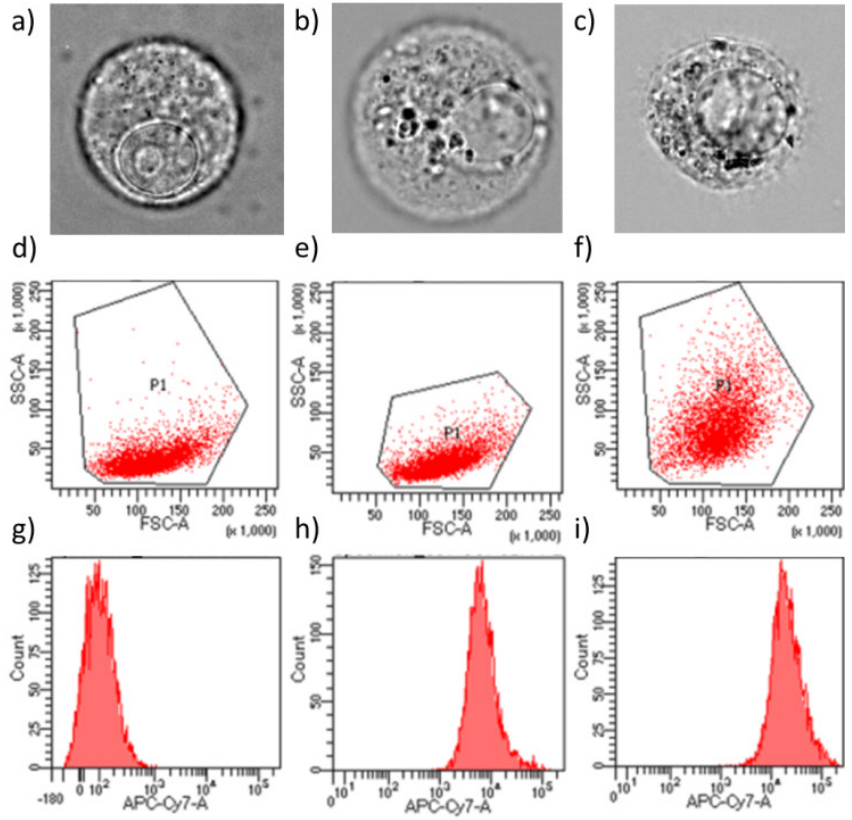

f)
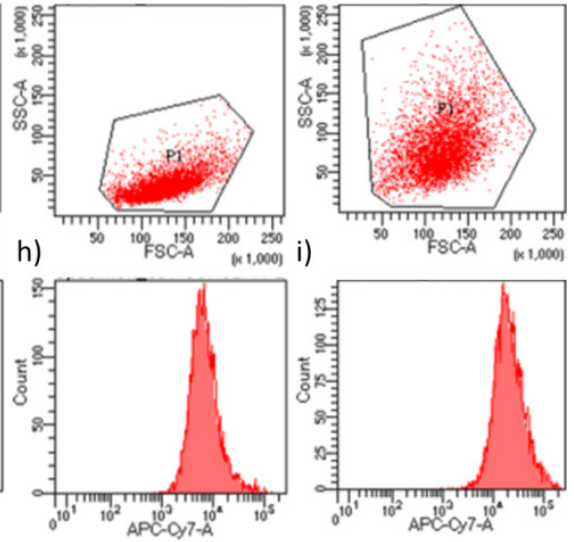

j)

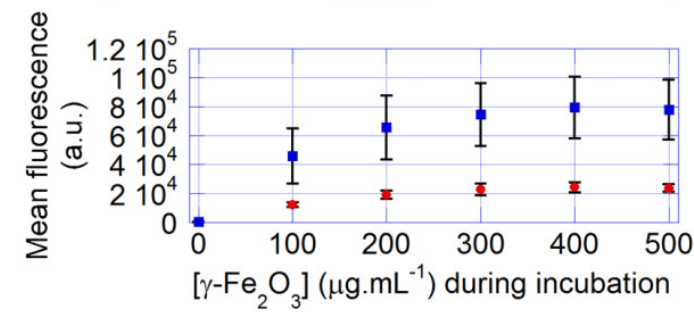

Fig. 3. Bright field microscopy images of a) control U87 cells, and U87 cells incubated with either b) monocore or c) multicore IONPs. Flow cytometry 2D plots of d) U87 cells, U87 cells incubated with e) monocore and f) multicore IONPs. Fluorescence histograms of g) U87 cells, U87 cells incubated with h) monocore and i) multicore IONPs. j) Mean monocore (red circles) and multicore (blue squares) IONPs. Error bars represent statistical scatter.

The cells incubated with monocore or multicore IONPs were detached from the surface of the culture plate for flow cytometry analysis. Under optical bright field microscopy, the cell membrane, nuclear membrane and nucleolus were visible for the control U87 cell, along with smaller un-resolved structures in the cytoplasm (Fig. 3a). Spherical structures with high contrast appeared when the cells were incubated with either monocore (Fig. 3b) or multicore IONPs (Fig. 3c). These structures most likely correspond to lysosomes encapsulating the IONPs, leading to dark-coloured objects. The observation cytometry analyses on a large number of cells $(100,000)$ providing statistically relevant results. The $2 \mathrm{D}$ multi-parametric plots of the forward scatter channel (FSC) that is proportional to the cell size vs the side scatter channel (SSC) representing the granularity and structural complexity inside the cells were

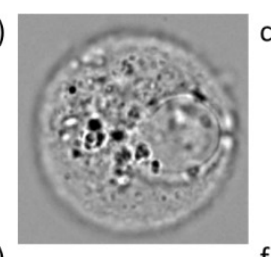
fluorescence of cells as a function of IONP concentration during incubation for of these microscopic structures was complemented by flow compared among the different conditions. Control U87 cells (Fig. 3d) and U87 cells incubated with monocore IONPs (Fig. 3e) exhibited similar 2D dot plots, while U87 cells incubated with multicore IONPs (Fig. 3f) had a broader and larger distribution of SSC values. In all three cases, the cell sizes were similar, as confirmed by bright field microscopy, while the internal granularity of the U87 cells incubated with multicore IONPs was more diverse and complex, leading to a stronger side scattering of the laser light. Comparison of flow cytometry 2D plots thus suggests a higher internalisation of multicore IONPs as compared to monocore IONPs, with possibly a higher density of lysosomes. The total fluorescence in the DY700 channel of each of the cell cultures was measured by defining using polygon gate selections on the $2 \mathrm{D}$ plots, integrating the signal of each individual cell and reporting the total counts on single-parameter histograms (Fig. 3g-i). Control U87 cells exhibited low auto-fluorescence level and behave as a single homogeneous population on the selected polygon gate, while U87 cells incubated with IONPs exhibited a high fluorescence intensity that increased by increasing the IONP concentration. Histograms representing single populations in all cases hinted that the internalisation happens in small fractions, and that all the cells incubated with IONPs have internalised them as they are all fluorescent. The integrated fluorescence levels of samples at different incubation IONP concentrations (Fig. 3j) show linear behaviour, until reaching a plateau value. This plot also evidenced around four-fold higher internalisation of the multicore IONPs as compared to monocore IONPs at a given incubation concentration. The same ratio was found between the plateaus of maximal IONP mass internalised per cell, for both types of IONP morphologies. d)

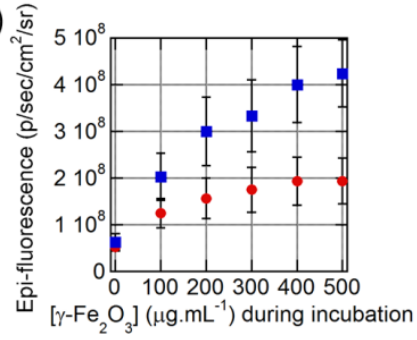

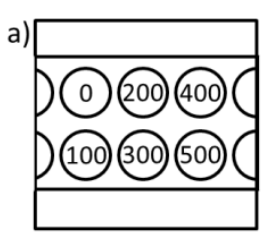

b)

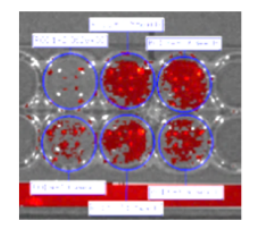

c)

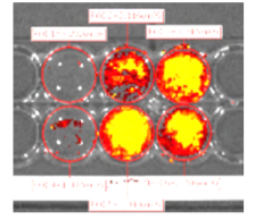

e)

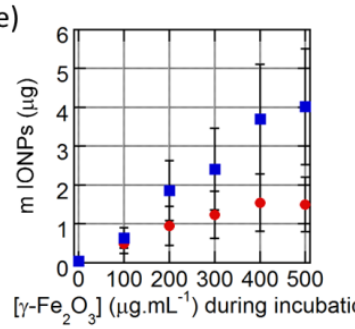

Fig. 4. a) Scheme representing the concentration of IONPs $\left(\mu \mathrm{g} \cdot \mathrm{mL}^{-1}\right)$ in the wells during cell incubation. Fluorescence measurement of $\mathbf{b}$ ) monocore and c) multicore IONPs internalised in U87 cells 24 hours after incubation. d) Epi-fluorescence of the cells for monocore (red circles) and multicore (blue square) IONPs. e) Quantity of monocore (red circles) and multicore (blue squares) IONPs internalised in the cells deduced by prior fluorescence calibration with known IONP amounts. 

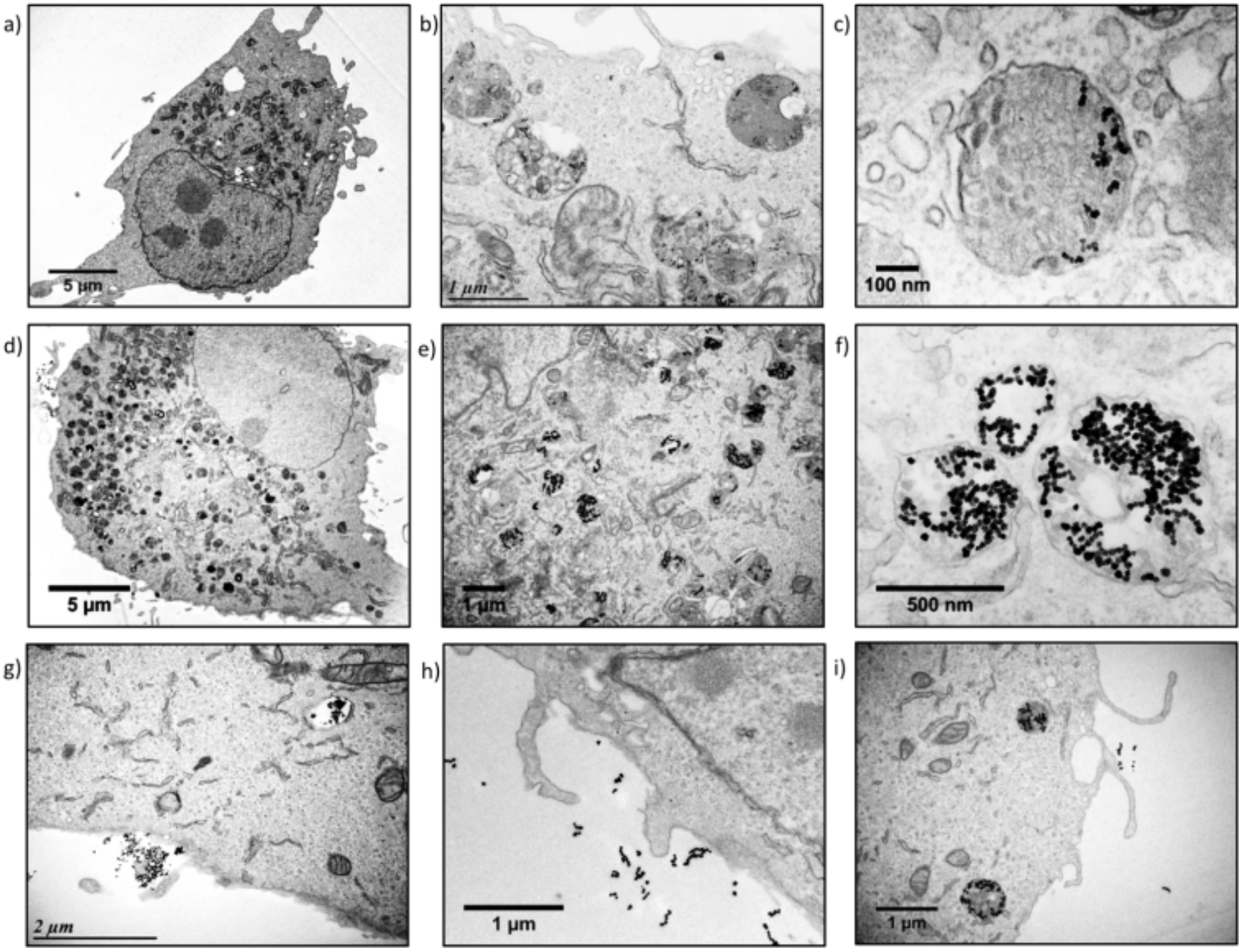

Fig. 5. U87 cell incubated with a-c) monocore or $\mathbf{d - f )}$ multicore IONPs. g-i) Internalisation pathways of IONPs in U87 cells.

The fluorescence of the DY700-labelled IONPs taken up by the cells was also detected directly on the culture plates by fluorescence reflectance imaging (FRI), a non-destructive technique complementary to flow cytometry that corresponds to spatial visualisation of the fluorescence signal on a camera. As for flow cytometry measurements, six different conditions of incubation during $24 \mathrm{~h}$ at increasing IONP concentrations were experimented (Fig. 4a). The fluorescence signal in each well was relatively homogeneous, as the cells spread over the whole surface available. Visually, the fluorescence intensity of cells incubated with monocore IONPs (Fig. 4b) was lower than with multicore IONPs (Fig. 4c). The average fluorescence signal at each incubation condition was quantified on a selected region of interest (ROI) and plotted vs incubated IONP concentration (Fig. 4d). The signal is initially proportional to IONP concentration, before plateauing. Like in flow cytometry results, multicore IONPs (squares) exhibited higher cellular internalisation as compared to monocore ones (circles). This intensity of FRI signal can be correlated to the total amount of IONPs contained in each well using pre-determined calibration curves. The relationships between the FRI levels on the images and the total IONP weights per well are reported in SI: The FRI intensities are well fitted by power laws of the IONP quantities expressed in $\mu \mathrm{g}$ per well both for multicore (Fig. S12d) and monocore IONPs (Fig. S13d). In both flow cytometry (Fig. 3j) and FRI (Fig. 4d) measurements, the fluorescence signal reached a plateau which could indicate saturation of the cells with IONPs. However, when plotting the total quantity of IONPs taken up by cells in each well vs incubated IONP concentration (Fig. 4e), a more linear relationship was obtained than expected from the raw fluorescence levels, after taking into account the calibration curves, well-fitted by power laws for both morphologies. The plateaus observed in the fluorescence levels measured by the two methods were therefore more likely ascribed to signal self-quenching rather than to saturation of the cells with IONPs. Considering the constant number of 5000 cells par well, the IONP mass taken up per $U 87$ cell after $24 \mathrm{~h}$ incubation at $500 \mu \mathrm{g} \cdot \mathrm{mL}^{-1}$ corresponded respectively to $\sim 300 \mathrm{pg} /$ cell for monocore IONPs and $\sim 800 \mathrm{pg} / \mathrm{cell}$ for multicore IONPs. These values seemed much larger than the $40 \mathrm{pg} /$ cell value reported in the pioneering work by Wilhelm et al. on IONP endocytosis in the HeLa cell line. ${ }^{31}$ However, when taking into account the difference of IONP diameters $(8.7 \mathrm{~nm}$ for the work of Wilhelm

This document is the Accepted Manuscript version of a Published Work that belongs to a special collection: Engineering Nanoparticles for Sensing and Biomedical Applications, appeared in final form in Mol. Syst. Des. Eng., 2017, 2(5), 629-639 (C) The Royal Society of Chemistry 2017 after peer review and technical editing by the publisher. To access the final edited and published work see http://dx.doi.org/10.1039/C7ME00061H 
et al., $14.5 \mathrm{~nm}$ for the monocore and $29.1 \mathrm{~nm}$ for the multicore IONPs here, the calculated numbers were found in a similar range of values, i.e. 23,38 and 12 million of IONPs per cell, respectively. In a recent work by Blanco-Andujar et al., loading rates similar to ours (up to $400 \mathrm{pg} / \mathrm{cell}$ ) were measured for IONPs of $17 \mathrm{~nm}$ diameter. ${ }^{32}$

The U87 cells were also analysed by transmission electron microscopy (TEM) to observe the sub-cellular localisation of the IONPs. TEM provides histological cross-sections at much higher resolution than confocal microscopy. U87 cells incubated with monocore (Fig. 5a-c) or multicore IONPs (Fig.5.d-f) were imaged after microtome preparation. The nanostructures of the cells were well observable thanks to the small thickness of the sample section $(65 \mathrm{~nm})$ and to staining with an osmium complex to enhance the contrast to electrons. Compartmentalisation being the main feature of eukaryotes, various membrane-bound organelles were indeed revealed inside the cytoplasm. The cell-membrane, mitochondria, nuclear membrane, nucleus and nucleolus were easily recognisable from their specific morphologies and localisation. The structure of the cells was bipolar, with a nucleus on one side and the organelles on the other side, while large portions of cytoplasm were left without apparent content. Lysosomes were recognisable by their spherical morphology and diameter of the order of $1 \mu \mathrm{m}$. They were also located on one side of the nucleus, in agreement with confocal microscopy images where blue nuclei and red lysosomes formed dipolar structures. The electron scattering contrast of the lysosomes depended on the quantity of IONPs contained inside, and on the lysosome ageing. Early endocytic compartments had a clear shade of grey while later ones were darker due to the fusion with other endocytic structures. Lysosomes were in greater numbers and encapsulated larger quantities of IONPs in the case of cells incubated with multicore IONPs. This observation correlated well with the data obtained by flow cytometry: With both monocore and multicore IONPs, the sizes of the cells were similar, but the cell granularity and the aspect of organelles appeared significantly different. The internalisation pathway could be observed on three micrographs (Fig. 5g-i), offering a glimpse of the successive stages when IONPs enter inside cells. A certain number of IONPs were also found outside the cells, although likely bond to them. As the preparation of the sample for TEM required several washes, IONPs outside cells were visible only in the close vicinity of the cell membrane. This suggests that there might be already an interaction between the cell surface and the IONPs, likely via decoration of polysaccharide chains linked to the plasma membrane (glycocalix) by the IONPs. The morphology adopted by the plasma membrane was similar to the macropinocytosis or phagocytosis pathways described in reviews and textbooks, ${ }^{33}$ appearing as a large budded portion of the plasma membrane towards the outer medium that curved back to engulf the NPs together with a volume of outer aqueous medium. ${ }^{31,34}$ This explains also why clear spherical structures having the same electron contrast as the outer medium of the cells were observed close to the inside of the membrane, while darker ones were observed closer to the nucleus, suggesting that the endocytic compartments travel from the boundaries of the cell towards its centre, becoming more and more dense along the process. ${ }^{35}$ In each case, the morphology and size of the IONPs were not modified inside the cells, meaning that the reported mechanisms of IONP degradation and iron metabolising did not start to occur within the $24 \mathrm{~h}$ incubation period. ${ }^{36}$

a)

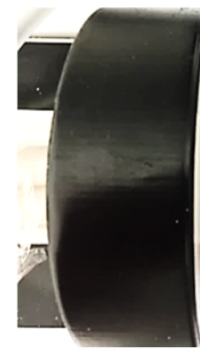

b)

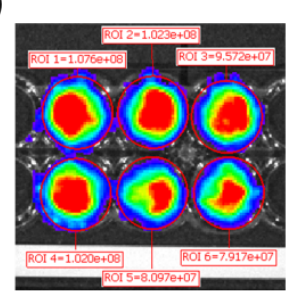

c)
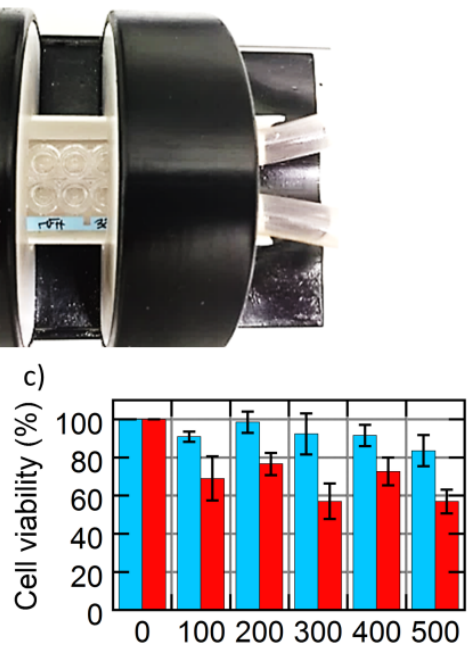

$\left[\mathrm{Fe}_{2} \mathrm{O}_{3}\right]\left(\mu \mathrm{g} \cdot \mathrm{mL}^{-1}\right)$ during incubation

d) e)
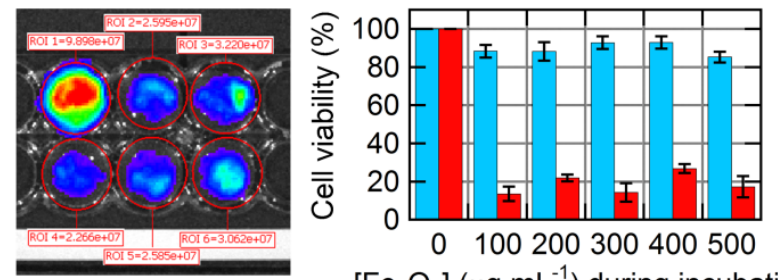

$\left[\mathrm{Fe}_{2} \mathrm{O}_{3}\right]\left(\mu \mathrm{g} \cdot \mathrm{mL}^{-1}\right)$ during incubation

Fig. 6. a) $D M 3$ inductor for applying an alternating magnetic field (AMF) on U87 glioblastoma cells. b) Bioluminescence imaging of U87 cells incubated at different concentrations of monocore IONPS after AMF application, and c) viability assay obtained from the BLI signal integrated in the ROIs (circles) before (blue) and after AMF application (red). d) BLI of U87 cells incubated at different concentrations of multicore IONPs after AMF application, and e) viability assay before (blue) and after AMF application (red).

After studying extensively the internalisation of IONPs in U87 glioblastoma cells, we focused on treating them by applying an alternating magnetic field (AMF), with a generator (DM100) and a 2-coil inductor (DM3) from the nanoscale Biomagnetics (nB) company (Zaragoza, Spain), specially designed for biological in vivo experimentation (Fig. 6a). The sample (16-well microscopy glass slide) was placed inside of a Helmoltz-like induction coil pair, thermalized at $37.5^{\circ} \mathrm{C}$ using a water jacket. The 2-coil configuration of the inductor helped observing the wells containing the cells while performing magnetic hyperthermia during $30 \mathrm{~min}$. The viability of the U87 cells was assayed by BLI readout based on luciferase activity, ${ }^{27}$ enabling to test the cytotoxicity of IONPs, either happening during IONP internalisation or after applying an external AMF to perform magnetic hyperthermia. Circular regions of interests (ROIs) were integrated on BLI images of U87 cells taken $24 \mathrm{~h}$ after AMF treatment to quantify the 
bioluminescence signal, for monocore (Fig. 6b) or multicore (Fig. 6d) IONPs. The cell viability was compared at varying IONP concentrations during incubation, before (blue) or after (red) the AMF application for $30 \mathrm{~min}$, for either monocore (Fig. 6c) or multicore (Fig. 6e) IONPs. For both morphologies, the cytotoxicity without the AMF application remained at a low level on all the range of incubation concentrations explored.

On the opposite, the AMF treatment caused a significant decrease of cell viability, with a death after $24 \mathrm{~h}$ of approximately $40 \%$ of the cells with monocore IONPs, whatever the incubated IONP concentration. In the case of multicore IONPs, cytotoxicity determined $24 \mathrm{~h}$ after magnetic hyperthermia was even more pronounced, leading to the death of the majority (80-90 \%) of the cells. Looking at these results, the multicore IONPs appeared more efficient as compared to monocore IONPs for the same conditions in a strategy of treatment of glioblastoma cells by magnetic hyperthermia. This result can be explained by several reasons. The first reason is the higher internalised quantity of the multicore IONPs, as observed by TEM, confocal microscopy, fluorescence imaging, and flow cytometry. Such higher mass of internalised heating agents leads theoretically to higher elevation of temperature, although a real temperature increase inside the cells induced by $\mathrm{MFH}$ is still a subject of debate in the community, due to their too small size for the heating power to compensate the dominant thermal losses into the surrounding environment. ${ }^{37}$

Non-thermal effects are also hypothesised to contribute to the cytotoxicity in cellular MFH, like for example a direct mechanical destabilisation of the cell membranes (the plasma membrane during IONP internalisation and later the lysosome membrane): Also called "nanoflowers" as ascribed to their morphology, multicore IONPs exhibit a pronounced surface roughness that might cause membrane deformation and tearing, when comparing the high magnification TEM view of lysosomes loaded with multicore IONPs (Fig. S23) to the micrograph of a lysosome filled with monocore IONPs (Fig. S20). Another often reported non-thermal effect is the Fenton reaction by which residual $\mathrm{Fe}^{2+}$ cations on the iron oxide surface can produce reactive oxygen species (ROS) oxidising phospholipids and causing the lysosome membrane rupture, as shown in several recent articles to be the main cause of intra-cellular MFH. ${ }^{38-40}$ Nanoflowers having a specific surface area typically $60 \%$ higher than smooth spherical IONPs, ${ }^{12}$ such non-thermal oxidative contribution to MFH would also be larger. The second reason is the highest SAR of the multi-core IONPs (expressed in $\mathrm{W} \cdot \mathrm{g}^{-1}$ ), meaning that they induce higher heating power efficiencies at equal iron oxide concentration compared to monocore spherical IONPs. Taking into account the two effects - SAR and internalised concentration of 265 $\mathrm{W} \cdot \mathrm{g}^{-1}$ and $800 \mathrm{pg} /$ cell for multicore IONPs as compared respectively to $134 \mathrm{~W} \cdot \mathrm{g}^{-1}$ and $300 \mathrm{pg} / \mathrm{cell}$ for monocore IONPs - the heating power is more than five times higher for multicore compared to monocore IONPs. The higher cytotoxicity at $24 \mathrm{~h}$ after 30 min treatment under an AMF with multi-cores (80-90 \% compared to $40 \%$ ) can be directly correlated to their more efficient heating power, maybe also combined with a mechanical disruption of the plasma and lysosomal membranes induced by their surface roughness.

\section{Experimental}

\section{IONP synthesis}

Magnetic iron oxide nanoparticles were synthesised by the polyol route, adapting the reaction conditions reported by Caruntu et al., ${ }^{9}$ i.e. by adding controlled fractions of water in the polyol reaction medium to drive the morphology of the IONPs obtained, as reported recently by our group. ${ }^{12}$ The NHSester modified DY700 fluorescent probe (Dyomics, Germany) was reacted with 1.5 equiv. of 2-aminoethylphosphonic acid (AEP) (Sigma Aldrich) in DMSO for $24 \mathrm{~h}$ at room temperature and under orbital agitation, before long-term storage at $-20^{\circ} \mathrm{C}$. Poly(ethylene glycol) methyl ether thiol (mPEG-SH, average molar mass $M_{n}=6,000 \mathrm{~g} \cdot \mathrm{mol}^{-1}$, Sigma Aldrich) was reacted with 1 equiv. of tris(2-carboxyethyl)phosphine hydrochloride (TCEP) (98\%, ACROS Organics) in $50 \mathrm{mM}$ phosphate buffer (PB) pH 7.4 for $24 \mathrm{~h}$ to reduce the disulphide bonds and (mPEG-S) ${ }_{2}$ dimer content, thus leading to reactive free thiol groups. In parallel, 5 equiv. AEP was reacted with 1 equiv. $N$-succinimidyl 4maleimidobutyrate (GMBS, TCl Europe) in PB for $24 \mathrm{~h}$ in an ice bath. Both solutions were then mixed and let to react for $24 \mathrm{~h}$, and finally purified by dialysis against milliQ water for $72 \mathrm{~h}$, using a $5 \mathrm{kDa}$ membrane, and replacing 6 times with milliQ water. $1 \% \mathrm{w} / \mathrm{w}$ equiv. AEP-DY700 were then grafted onto IONPs in water acidified to $\mathrm{pH}=2.5$ with dilute nitric acid. After $1 \mathrm{~h}, 30 \%$ (16\%) w/w of AEP-GMBS-PEG was added to the dispersion of monocore or multicore IONPs. These proportions led to theoretical grafting densities of $\sigma=1 / D^{2}=0.64$ molecular chains per $\mathrm{nm}^{2}$ or reduced tethered densities $\Sigma=\pi R_{\mathrm{G}}^{2} / D^{2}=15$ according to our calculations, using scaling laws reported by Devanand ${ }^{41}\left(R_{\mathrm{G}}(\mathrm{nm})=0.0215 \cdot M_{\mathrm{n}}^{0.583}\right)$ or by Le Coeur et al. ${ }^{42}\left(R_{\mathrm{G}}(\mathrm{nm})=0.066466 \cdot M_{\mathrm{n}}^{0.45224}\right)$, which are different but both lead to the same value $R_{\mathrm{G}}=3.4 \mathrm{~nm}$ for PEG of $M_{\mathrm{n}}=6,000 \mathrm{~g} \cdot \mathrm{mol}^{-1}$. After $2 \mathrm{~h}$ of reaction, the $\mathrm{pH}$ was neutralised with Tris $50 \mathrm{mM}$ and the solutions were purified from the excess of AEP-GMBS-PEG and AEP-DY700 by 3 cycles of centrifugation-redispersion $\left(18,000 \mathrm{~g}, 1 \mathrm{~h}\right.$ at $25^{\circ} \mathrm{C}, 30 \mathrm{~min}$ at $1^{\circ} \mathrm{C}$ to increase viscosity and avoid pellet dispersion before removing the supernatant).

\section{Cell line generation and culture}

U87 human glioma cell line was procured by the American Tissue Culture Collection (ATCC, Manassas, Virginia). The bioluminescent U87-CMV-lucF cell line generation was previously reported. ${ }^{26}$ Cells were cultivated in Dulbecco's modified Eagle's medium (DMEM, Invitrogen, Carlsbad, California) supplemented with $10 \%$ foetal bovine serum (FBS, Invitrogen), $1 \%$ antimycotic-antibiotic mix (PSA, Invitrogen), $1 \%$ nonessential amino acid (MEM NEAA, Invitrogen) and 50 $\mu \mathrm{g} \cdot \mathrm{mL}^{-1}$ Hygromycin B (Euromedex, Souffelweyersheim, France). Cell line was maintained in a humidified $5 \% \mathrm{CO}_{2}$ incubator at $37^{\circ} \mathrm{C}$. 


\section{Incubation of cells with IONPs}

Cells (5000 cells per well) were plated in 16 -well Nunc ${ }^{\text {TM }}$ LabTek $^{\circledR}$ microscopy chambers (Thermo Fisher Scientific) $24 \mathrm{~h}$ before experiments. They were then incubated with $100 \mu \mathrm{L}$ of determined concentrations of IONPs $(0,100,200,300,400$ or $500 \mu \mathrm{g} \cdot \mathrm{mL}^{-1}$ ) in supplemented DMEM for $24 \mathrm{~h}$. They were finally washed 2 times with $100 \mu \mathrm{L}$ of PBS and $100 \mu \mathrm{L}$ of fresh supplemented DMEM.

\section{Laser scanning confocal microscopy (LSCM)}

Cells (22,500 cells per well) were plated in 24-well plates $24 \mathrm{~h}$ before experiments and then incubated with IONPs conjugated to the NIR fluorescent probe DY700 (Dyomics $\mathrm{GmbH}$ ) for $24 \mathrm{~h}$ at $100 \mu \mathrm{g} \cdot \mathrm{mL}^{-1}$. They were washed with PBS, and their nucleus was stained with the blue fluorescent probe Hoechst 33342 (Thermo Fisher Scientific) at a concentration of $2 \mu \mathrm{g} \cdot \mathrm{mL}^{-1}$ for 5 $\min$ at $37{ }^{\circ} \mathrm{C}$. Finally, the lysosomes were specifically tagged with the green fluorescent probe Lysotracker $^{\text {TM }}$ at a concentration of $100 \mathrm{nM}$ for $1 \mathrm{~min}$ at RT. The cells were harvested with trypsin for $5 \mathrm{~min}$ at RT, suspended in PBS and centrifuged for $5 \mathrm{~min}$ at $300 \mathrm{~g}$. They were re-suspended in 200 $\mu \mathrm{L}$ of PBS-EDTA $2 \mathrm{mM}$ supplemented with $0.5 \%$ of FBS, and kept on ice to prevent adhesion, before visualisation. Laser scanning confocal microscopy (LSCM) images were acquired on an inverted Leica TCS SP5 microscope equipped with an HCX PL APO 63× NA 1.4 oil immersion objective in fluorescence mode. Samples $(\approx 15 \mu \mathrm{L})$ were injected in a homemade chamber that was sealed to prevent evaporation. The laser outputs are controlled via the acousto-optical tunable filter (AOTF) and the three collection windows using the acousto-optical beam splitter (AOBS) and photomultiplicator (PMT) detectors as follows: Blue Hoechst 33342 was excited with a laser diode at $405 \mathrm{~nm}(3 \%)$ and measured with emission setting at 410-510 $\mathrm{nm}$, green Lysotracker ${ }^{\mathrm{TM}}$ was excited with a DPSS diode at 561 $\mathrm{nm}(50 \%)$ using a window at 570-650 $\mathrm{nm}$ and red DY700 was excited with a Helium-Neon laser at $633 \mathrm{~nm}$ (80\%) using a window at $640-770 \mathrm{~nm}$. LSCM images were collected using the microscope in sequential mode to avoid overlapping of the emissions between the channels with a line average of 4 and a format of $1024 \times 1024$ pixels. The transmission mode images were provided from the Helium-Neon laser at $633 \mathrm{~nm} \mathrm{(10 \% ).}$ PMT gain and offset configurations were set up on control cells so as to correct images from green and red auto-fluorescence.

\section{Flow cytometry}

Cells $(22,500$ cells per well) were plated in 24-well plates $24 \mathrm{~h}$ before experiments and then incubated with $450 \mu \mathrm{L}$ of determined concentrations of IONPs (0, 100, 200, 300, 400 or $500 \mu \mathrm{g} \cdot \mathrm{mL}^{-1}$ ). After $24 \mathrm{~h}$ incubation, the cells were washed 2 times with PBS, harvested with trypsin and washed with PBS. Cells were re-suspended in $200 \mu \mathrm{L}$ of PBS-EDTA $2 \mathrm{mM}$ supplemented with $0.5 \%$ of FBS and analysed by flow cytometry using a BD FACSCanto ${ }^{\mathrm{TM}}$ setup (BD Biosciences). Samples were analysed using an excitation laser at $633 \mathrm{~nm}$, absorption with the APC-Cy7 canals at $680 \mathrm{~nm}$, the forward scatter channel (FSC) voltage being fixed at $160 \mathrm{~V}$ and the side scatter channel (SSC) voltage fixed at $160 \mathrm{~V}$.

\section{Fluorescence and bioluminescence imaging}

Fluorescence reflectance imaging (FRI) and bioluminescence imaging (BLI) were performed at Vivoptic (UMS 3767 - Univ. Bordeaux) by using a Lumina LT instrument (Perkin Elmer Inc., Boston, MA, USA). For BLI, the cells were incubated for $5 \mathrm{~min}$ with a $0.6 \mathrm{mM}$ solution of D-luciferin in PBS (Promega, Madison, WI, USA). Bioluminescence images ( $1 \mathrm{~min}, 4 \times 4$ binning) and photographs (100 ms) were acquired successively. Fluorescence images $(1 \mathrm{~s}$, excitation at $640 \mathrm{~nm}$, 695-770 nm filter emission, $4 \times 4$ binning) and photographs (100 $\mathrm{ms}$ ) were acquired successively. Images were analysed using Living Image software by defining regions of interests (ROI) and integrating all the FRI or BLI photons coming from inside. The intensities were converted into absolute units of radiance (photons $\cdot \mathrm{s}^{-1} \cdot \mathrm{cm}^{-2} \cdot \mathrm{sr}^{-1}$ ) by internal calibration of manufacturer.

\section{Transmission electron microscopy (TEM)}

Glial U87 cells were cultivated on 16-well optical glass supports (Nunc ${ }^{T M} 178599$ Lab-Tek $^{\circledR}$ Chamber Slide $^{\text {TM }}$ System, Glass, Volume: 0.1-0.2 mL, Culture Area: $0.4 \mathrm{~cm}^{2} /$ well). After incubation $(24 \mathrm{~h})$ with the IONPs, cells were washed two times with PBS, fixed with $1.6 \%(\mathrm{v} / \mathrm{v})$ paraformaldehyde $2 \%(\mathrm{v} / \mathrm{v})$ glutaraldehyde in $0.08 \mathrm{M}$ cacodylate buffer $(\mathrm{pH}$ 7.4) during 30 min minimum at room temperature (RT), washed in $0.1 \mathrm{M}$ cacodylate buffer $(\mathrm{pH} \mathrm{7.4)}$ and then post-fixed in a mix of $1 \%$ osmium tetroxide $(\mathrm{v} / \mathrm{v}) / 1 \%$ potassium ferricyanide $\mathrm{K}_{3} \mathrm{Fe}(\mathrm{CN})_{6}$ $(p / v)$ in $0.1 \mathrm{M}$ cacodylate buffer during 2 hours on ice in the dark. After washing in water, samples were stained in block in $0.5 \%(\mathrm{p} / \mathrm{v})$ aqueous uranyl acetate solution during $30 \mathrm{~min}$, in the dark, at RT. Subsequently, cells were washed in water then dehydrated through a series of graded ethanol and embedded in a mixture of pure ethanol and epoxy resin (Epon 812, Delta Microscopies, Toulouse, France) 50/50 (v/v) during $2 \mathrm{~h}$ and then in $100 \%$ resin overnight at RT. The polymerisation of the resin was carried out over a period between $24-48 \mathrm{~h}$ at $60^{\circ} \mathrm{C}$. Samples were then sectioned using a diamond knife (Diatome, Biel-Bienne, Switzerland) on an ultramicrotome (EM UCT, Leica Microsystems, Vienna, Austria). Ultrathin sections (65 $\mathrm{nm}$ ) were picked up on copper grids and then stained with Uranyless (Delta Microscopies, Toulouse, France) and lead citrate. Grids were examined with a Transmission Electron Microscope (H7650, Hitachi, Tokyo, Japan) at $80 \mathrm{kV}$ in High Contrast Mode.

\section{Magnetic field hyperthermia (MFH)}

The applied radiofrequency AMF was generated using a DM3 applicator for in vivo MFH (nB nanoScale Biomagnetics, Zaragoza, Spain). Cells were thermalized at $37.5{ }^{\circ} \mathrm{C}$ using a water bath connected to a water tubing jacket. The temperature of the sample was monitored using a fibre optic sensor (Neoptix ${ }^{\mathrm{TM}}$, Québec city, Canada). The alternating magnetic field was set on a frequency of $473 \mathrm{kHz}, 12 \mathrm{kA} \cdot \mathrm{m}^{-1}$ of amplitude, and applied for $30 \mathrm{~min}$. The cells were put back in 
the incubator at $37{ }^{\circ} \mathrm{C} / 5 \% \mathrm{CO}_{2}$ and observed by bioluminescence and fluorescence imaging $24 \mathrm{~h}$ later.

\section{Conclusions}

In this article, we reported the surface modification of IONPs of two different sizes and morphologies (monocores or multicores, of respectively 14.5 and $29.1 \mathrm{~nm}$ outer diameters), with two molecules: A NIR fluorescent probe (DY700) to allow tracking of the nanoparticles in cells, and a 6,000 MW PEG stabilising brush. This molecular design was completed through a one-pot convergent strategy, in aqueous conditions, and on stable IONPs, i.e. individually dispersed. The modified IONPs obtained were readily dispersed in water, and could be purified by a simple centrifugation-redispersion process. The interaction of these IONPs with cancerous cells was investigated using a bioluminescent human glioblastoma cell line, genetically modified to express the luciferase enzyme as a convenient read-out of cell viability. IONPs accumulated in lysosomes, as firstly observed by confocal microscopy, using the Lysotracker ${ }^{\mathrm{TM}}$ green dye. There was a direct correlation between the quantity of IONPs internalised and the concentration of IONPs during incubation, as evidenced by flow cytometry and fluorescence imaging. The number of IONPs internalised in $24 \mathrm{~h}$ in each cell was evaluated around a few tens of million, in agreement with literature. With much higher resolution, TEM images show that the morphology of the IONPs was conserved after incubation, even after $24 \mathrm{~h}$, meaning that such PEGylated IONPs are fairly insensitive to the mechanisms of degradation occurring inside of the lysosomes and keep their heating efficiencies, at least at this time scale. The ability of these IONPs to kill cells by magnetic field hyperthermia was studied using a commercial DM3 set-up (nB) by applying an AMF amplitude, frequency, and duration of application suitable for medical applications. The cell viability was assessed quantitatively based on the bioluminescence signal of cells $24 \mathrm{~h}$ after the AMF application. The higher efficiency of the multicore IONPs compared to the monocore IONPS was evidenced by an increased cytotoxicity that appeared also to be independent of the iron oxide dose. Therefore multicore IONPs or nanoflowers are particularly suitable agents for magnetic hyperthermia treatment of cancerous cells, and a lot of research is currently on-going in our group and others to design molecular coatings providing further functionalities such as cancer cell targeting, ${ }^{43}$ or anticancer drug delivery activated by the AMF application. ${ }^{44}$

\section{Conflicts of interest}

There are no conflicts of interest to declare.

\section{Acknowledgements}

This article is based upon work from COST Action RADIOMAG (TD1402), supported by the European Cooperation in Science and Technology association and by the Agence Nationale de la
Recherche (Grant ANR-13-BS08-0017 MagnetoChemoBlast). G.H.'s doctoral fellowship was funded by the 2014 call of the Department of Science and Technology of the University of Bordeaux (APUB1-ST2014).

Electron microscopy studies were conducted at the Bordeaux Imaging Center - Bordeaux University, a Core facility of the national infrastructure "France Biolmaging" (ANR-10-INBS-04 FranceBiolmaging). The $\mathrm{nB} D \mathrm{DM} 3$ setup for in vivo magnetic hyperthermia was co-funded by the 2014-2016 Défi Nano call of the CNRS Mission pour l'Interdisciplinarité (Nano-M2T).

\section{Notes and references}

1. R. L. Siegel, K. D. Miller and A. Jemal, Cancer statistics, 2017, CA: A Cancer Journal for Clinicians, 2017, 67, 730.

2. D. Parkin, S. Whelan, J. Ferlay, L. Teppo and D. Thomas, Cancer in Five Continents Vol. VIII, IARC Scientific Publications, Lyon, France, 2002.

3. C. Adamson, O. O. Kanu, A. I. Mehta, C. Di, N. Lin, A. K. Mattox and D. D. Bigner, Glioblastoma multiforme: a review of where we have been and where we are going, Expert Opinion on Investigational Drugs, 2009, 18, 1061-1083.

4. M. S. Walid, Prognostic Factors for Long-Term Survival after Glioblastoma, The Permanente Journal, 2008, 12, 45-48.

5. K. Maier-Hauff, R. Rothe, R. Scholz, U. Gneveckow, P. Wust, B. Thiesen, A. Feussner, A. von Deimling, N. Waldoefner, R. Felix and A. Jordan, Intracranial Thermotherapy using Magnetic Nanoparticles Combined with External Beam Radiotherapy: Results of a Feasibility Study on Patients with Glioblastoma Multiforme, Journal of Neuro-Oncology, 2007, 81, 5360.

6. K. Maier-Hauff, F. Ulrich, D. Nestler, H. Niehoff, P. Wust, B. Thiesen, H. Orawa, V. Budach and A. Jordan, Efficacy and safety of intratumoral thermotherapy using magnetic iron-oxide nanoparticles combined with external beam radiotherapy on patients with recurrent glioblastoma multiforme, Journal of Neuro-Oncology, 2011, 103, 317-324.

7. A. C. Silva, T. R. Oliveira, J. B. Mamani, S. M. F. Malheiros, L. Malavolta, L. F. Pavon, T. T. Sibov, E. Amaro, A. Tannús, E. L. G. Vidoto, M. J. Martins, R. S. Santos and L. F. Gamarra, Application of hyperthermia induced by superparamagnetic iron oxide nanoparticles in glioma treatment, International Journal of Nanomedicine, 2011, 6, 591-603.

8. E. A. Périgo, G. Hemery, O. Sandre, D. Ortega, E. Garaio, F. Plazaola and F. J. Teran, Fundamentals and advances in magnetic hyperthermia, Applied Physics Reviews, 2015, 2, 041302.

9. D. Caruntu, G. Caruntu, Y. Chen, C. J. O'Connor, G. Goloverda and V. L. Kolesnichenko, Synthesis of Variable-Sized Nanocrystals of Fe3O4 with High Surface 
Reactivity, Chemistry of Materials, 2004, 16, 5527 5534.

10.

L. Lartigue, P. Hugounenq, D. Alloyeau, S. P. Clarke, M. Lévy, J.-C. Bacri, R. Bazzi, D. F. Brougham, C. Wilhelm and F. Gazeau, Cooperative Organization in Iron Oxide Multi-Core Nanoparticles Potentiates Their Efficiency as Heating Mediators and MRI Contrast Agents, ACS Nano, 2012, 6, 10935-10949.

11. P. Hugounenq, M. Levy, D. Alloyeau, L. Lartigue, E. Dubois, V. Cabuil, C. Ricolleau, S. Roux, C. Wilhelm, F. Gazeau and R. Bazzi, Iron Oxide Monocrystalline Nanoflowers for Highly Efficient Magnetic Hyperthermia, J. Phys. Chem. C, 2012, 116, $15702-$ 15712.

12. G. Hemery, A. Keyes Jr., C., E. Garaio, I. Rodrigo, J. A. Garcia, F. Plazaola, E. Garanger and O. Sandre, Tuning sizes, morphologies, and magnetic properties of monocore versus multicore iron oxide nanoparticles through the controlled additon of water in the polyol synthesis, Inorganic Chemistry, 2017, 56, 8232-8243.

13. R. Hergt and S. Dutz, Magnetic particle hyperthermiabiophysical limitations of a visionary tumour therapy, Journal of Magnetism and Magnetic Materials, 2007, 311, 187-192.

14. A. Kostopoulou, K. Brintakis, M. Vasilakaki, K. N. Trohidou, A. P. Douvalis, A. Lascialfari, L. Manna and A. Lappas, Assembly-mediated interplay of dipolar interactions and surface spin disorder in colloidal maghemite nanoclusters, Nanoscale, 2014, 6, 37643776.

15. D. Sakellari, K. Brintakis, A. Kostopoulou, E. Myrovali, K. Simeonidis, A. Lappas and M. Angelakeris, Ferrimagnetic nanocrystal assemblies as versatile magnetic particle hyperthermia mediators, Materials Science and Engineering: C, 2016, 58, 187-193.

16. E. Wetterskog, A. Castro, L. Zeng, S. Petronis, D. Heinke, E. Olsson, L. Nilsson, N. Gehrke and P. Svedlindh, Size and property bimodality in magnetic nanoparticle dispersions: single domain particles vs. strongly coupled nanoclusters, Nanoscale, 2017, 9, 4227-4235.

17. A. Walter, A. Garofalo, P. Bonazza, F. Meyer, H. Martinez, S. Fleutot, C. Billotey, J. Taleb, D. FelderFlesch and S. Begin-Colin, Effect of the Functionalization Process on the Colloidal, Magnetic Resonance Imaging, and Bioelimination Properties of Mono- or Bisphosphonate-Anchored Dendronized Iron Oxide Nanoparticles, ChemPlusChem, 2017, 82, 647659.

18. S. S. Eamegdool, M. W. Weible, B. T. T. Pham, B. S. Hawkett, S. M. Grieve and T. Chan-ling, Ultrasmall superparamagnetic iron oxide nanoparticle prelabelling of human neural precursor cells, Biomaterials, 2014, 35, 5549-5564.

19. H. M. Vishwasrao, A. M. Master, Y. G. Seo, X. M. Liu, N. Pothayee, Z. Zhou, D. Yuan, M. D. Boska, T. K. Bronich, R. M. Davis, J. S. Riffle, M. Sokolsky-Papkov and A. V.
Kabanov, Luteinizing Hormone Releasing HormoneTargeted Cisplatin-Loaded Magnetite Nanoclusters for Simultaneous MR Imaging and Chemotherapy of Ovarian Cancer, Chemistry of Materials, 2016, 28, 3024-3040.

20. G. Ramniceanu, B. T. Doan, C. Vezignol, A. Graillot, C. Loubat, N. Mignet and J. F. Berret, Delayed hepatic uptake of multi-phosphonic acid poly(ethylene glycol) coated iron oxide measured by real-time magnetic resonance imaging, RSC Advances, 2016, 6, 6378863800.

21. A. Lassenberger, O. Bixner, T. Gruenewald, H. Lichtenegger, R. Zirbs and E. Reimhult, Evaluation of High-Yield Purification Methods on Monodisperse PEGGrafted Iron Oxide Nanoparticles, Langmuir, 2016, 32, 4259-4269.

22. C. Barrera, A. P. Herrera, N. Bezares, E. Fachini, R. Olayo-Valles, J. P. Hinestroza and C. Rinaldi, Effect of poly(ethylene oxide)-silane graft molecular weight on the colloidal properties of iron oxide nanoparticles for biomedical applications, Journal of Colloid and Interface Science, 2012, 377, 40-50.

23. S. Bae, J. W. Jeoung, M. Jeun, J.-t. Jang, J. H. Park, Y. J. Kim, K. Lee, M. Kim, J. Lee, H. M. Hwang, S. H. Paek and K. H. Park, Magnetically softened iron oxide (MSIO) nanofluid and its application to thermally-induced heat shock proteins for ocular neuroprotection, Biomaterials, 2016, 101, 165-175.

24. J. Pauli, T. Vag, R. Haag, M. Spieles, M. Wenzel, W. A. Kaiser, U. Resch-Genger and I. Hilger, An in vitro characterization study of new near infrared dyes for molecular imaging, European Journal of Medicinal Chemistry, 2009, 44, 3496-3503.

25. C. Germain-Genevois, O. Garandeau and F. Couillaud, Detection of Brain Tumors and Systemic Metastases Using NanoLuc and Fluc for Dual Reporter Imaging, Molecular Imaging and Biology, 2016, 18, 62-69.

26. P.-Y. Fortin, C. Genevois, A. Koenig, E. Heinrich, I. Texier and F. Couillaud, Detection of brain tumors using fluorescence diffuse optical tomography and nanoparticles as contrast agents, BIOMEDO, 2012, 17, 126004-126004.

27. C. Rome, H. Loiseau, J. Arsaut, V. Roullot and F. Couillaud, Diversity of Contactin mRNA in Human Brain Tumors, Molecular Carcinogenesis, 2006, 45, 774-785.

28. W. J. Brittain and S. Minko, A structural definition of polymer brushes, Journal of Polymer Science Part A: Polymer Chemistry, 2007, 45, 3505-3512.

29. B. Gilbert, J. E. Katz, N. Huse, X. Zhang, C. Frandsen, R. W. Falcone and G. A. Waychunas, Ultrafast electron and energy transfer in dye-sensitized iron oxide and oxyhydroxide nanoparticles, Physical Chemistry Chemical Physics, 2013, 15, 17303-17313.

30. V. Connord, P. Clerc, N. Hallali, D. El Hajj Diab, D. Fourmy, V. Gigoux and J. Carrey, Real-Time Analysis of Magnetic Hyperthermia Experiments on Living Cells 
under a Confocal Microscope, Small, 2015, 11, $2437-$ 2445.

31.

C. Wilhelm, F. Gazeau, J. Roger, J.-N. Pons and J.-C. Bacri, Interaction of Anionic Superparamagnetic Nanoparticles with Cells: Kinetic Analyses of Membrane Adsorption and Subsequent Internalization, Langmuir, 2002, 18, 8148-8155.

32. C. Blanco-Andujar, D. Ortega, P. Southern, S. A. Nesbitt, N. T. K. Thanh and Q. A. Pankhurst, Real-time tracking of delayed-onset cellular apoptosis induced by intracellular magnetic hyperthermia, Nanomedicine, 2016, 11, 121-136.

33. H. Hillaireau and P. Couvreur, Nanocarriers' entry into the cell: relevance to drug delivery, Cell. Mol. Life Sci., 2009, 66, 2873-2896.

34. B. Kann, H. L. Offerhaus, M. Windbergs and C. Otto, Raman microscopy for cellular investigations - From single cell imaging to drug carrier uptake visualization, Advanced Drug Delivery Reviews, 2015, 89, 71-90.

35. N. Oh and J.-H. Park, Endocytosis and exocytosis of nanoparticles in mammalian cells, International Journal of Nanomedicine, 2014, 9, 51-63.

36. M. Levy, N. Luciani, D. Alloyeau, D. Elgrabli, V. Deveaux, C. Pechoux, S. Chat, G. Wang, N. Vats, F. Gendron, S. L. Cécile Factor, A. Luciani, C. Wilhelm and F. Gazeau, Long term in vivo biotransformation of iron oxide nanoparticles, Biomaterials, 2011, 32, 3988-3999.

37. G. Baffou, H. Rigneault, D. Marguet and L. Jullien, A critique of methods for temperature imaging in single cells, Nat Meth, 2014, 11, 899-901.

38. M. Domenech, I. Marrero-Berrios, M. Torres-Lugo and C. Rinaldi, Lysosomal Membrane Permeabilization by Targeted Magnetic Nanoparticles in Alternating Magnetic Fields, ACS Nano, 2013, 7, 5091-5101.

39. C. Sanchez, D. El Hajj Diab, V. Connord, P. Clerc, E. Meunier, B. Pipy, B. Payré, R. P. Tan, M. Gougeon, J. Carrey, V. Gigoux and D. Fourmy, Targeting a GProtein-Coupled Receptor Overexpressed in Endocrine Tumors by Magnetic Nanoparticles To Induce Cell Death, ACS Nano, 2014, 8, 1350-1363.

40. R. J. Wydra, P. G. Rychahou, B. M. Evers, K. W. Anderson, T. D. Dziubla and J. Z. Hilt, The role of ROS generation from magnetic nanoparticles in an alternating magnetic field on cytotoxicity, Acta Biomaterialia, 2015, 25, 284-290.

41. K. Devanand and J. C. Selser, Asymptotic Behavior and Long-Range Interactions in Aqueous Solutions of Poly(ethylene oxide), Macromolecules, 1991, 24, 59435947.

42. C. Le Coeur, J. Teixeira, P. Busch and S. Longeville, Compression of random coils due to macromolecular crowding: Scaling effects, Physical Review E, 2010, 81, 061914.

43. K. Ulbrich, K. Holá, V. Šubr, A. Bakandritsos, J. Tuček and R. Zbořil, Targeted Drug Delivery with Polymers and Magnetic Nanoparticles: Covalent and
Noncovalent Approaches, Release Control, and Clinical Studies, Chemical Reviews, 2016, 116, 5338-5431.

D. Mertz, O. Sandre and S. Bégin-Colin, Drug releasing nanoplatforms activated by alternating magnetic fields, Biochimica et Biophysica Acta (BBA) - General Subjects, 2017, 1861, 1617-1641. 


\section{Electronic Supplementary Information (ESI)}
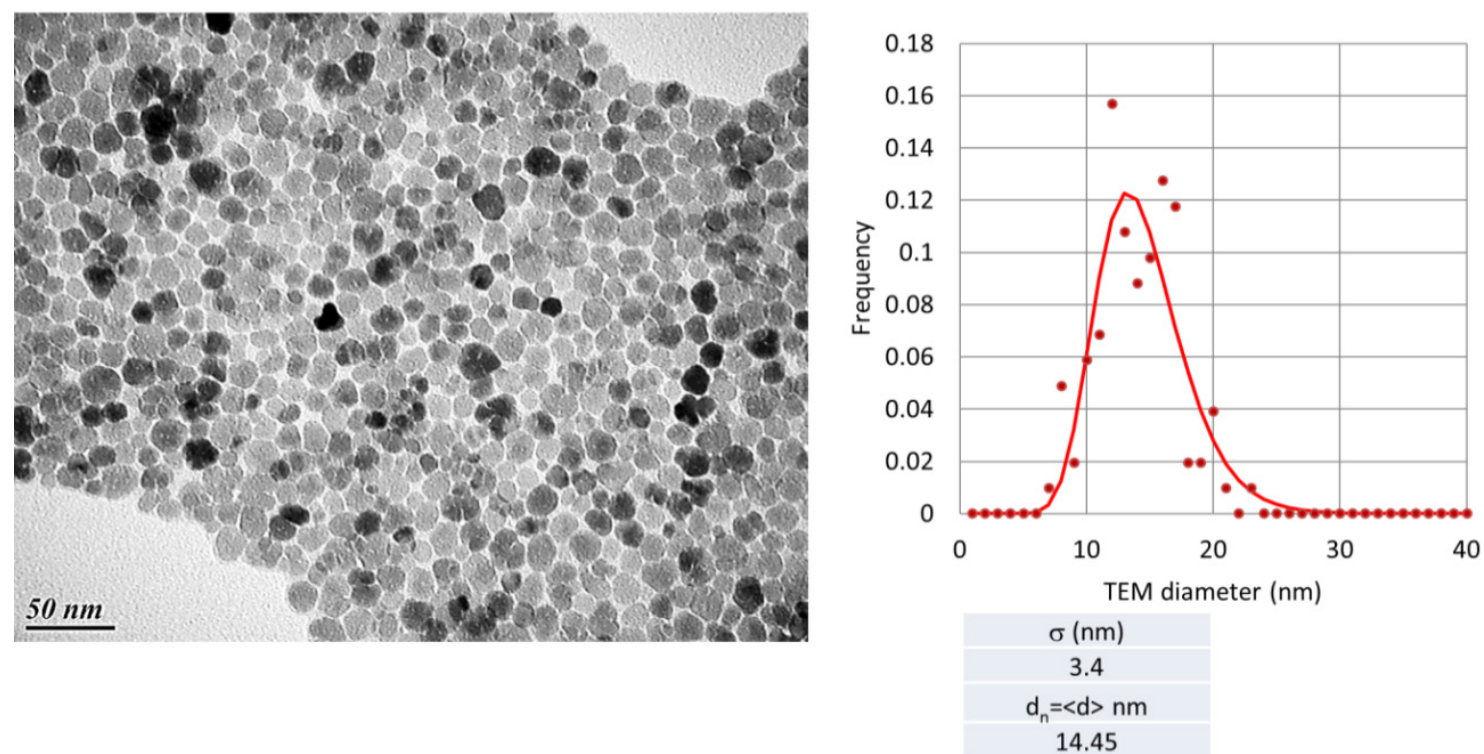

Fig. S1. TEM micrograph and size distribution of monocore IONPS
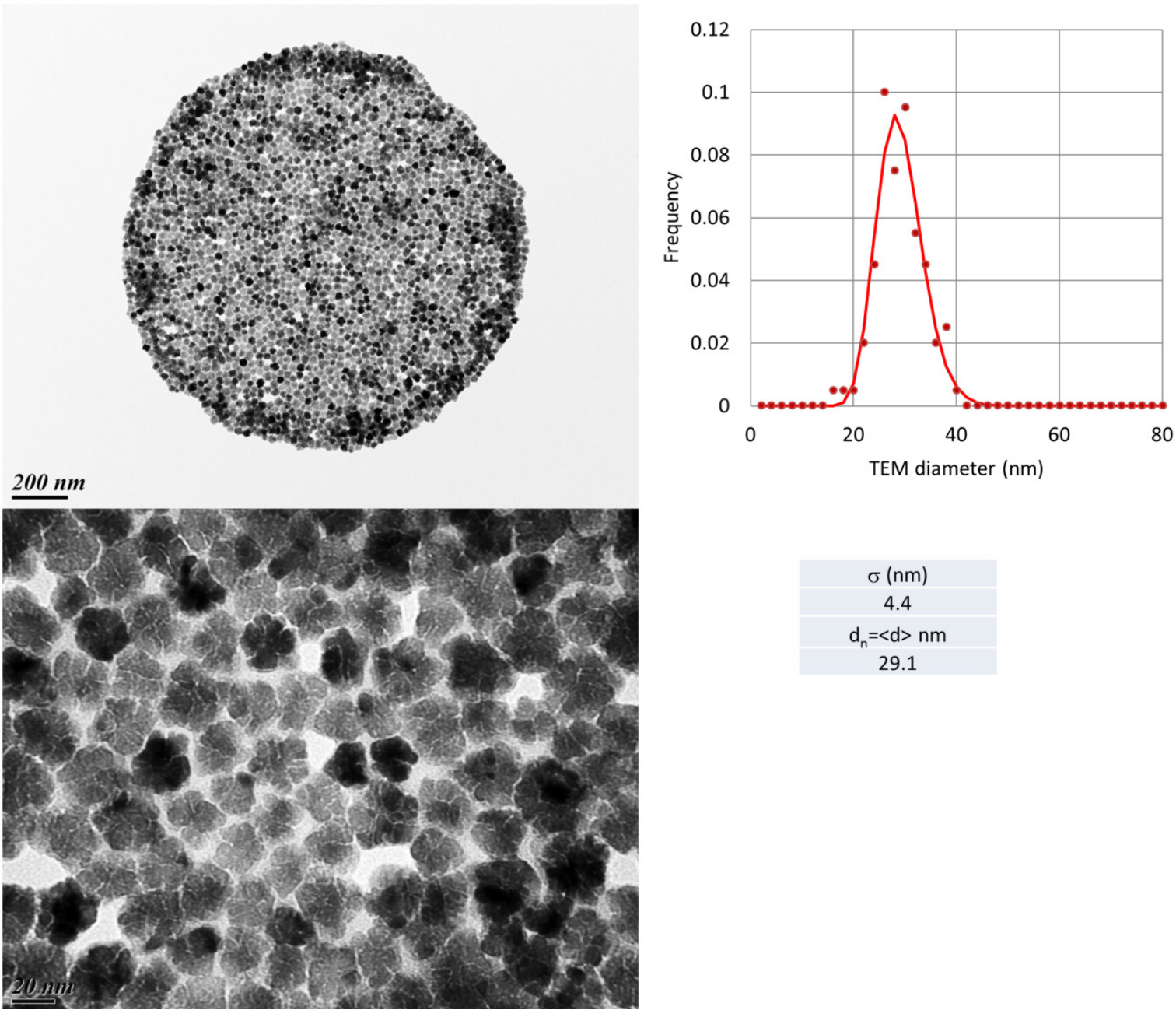

This document is the Accepted Manuscript version of a Published Work that belongs to a special collection: Engineering Nanoparticles for Sensing and Biomedical Applications, appeared in final form in Mol. Syst. Des. Eng., 2017, 2(5), 629-639 @ The Royal Society of Chemistry 2017 after peer review and technical editing by the publisher. To access the final edited and published work see http://dx.doi.org/10.1039/C7ME00061H 
Fig. S2. TEM micrograph and size distribution of multicore IONPS

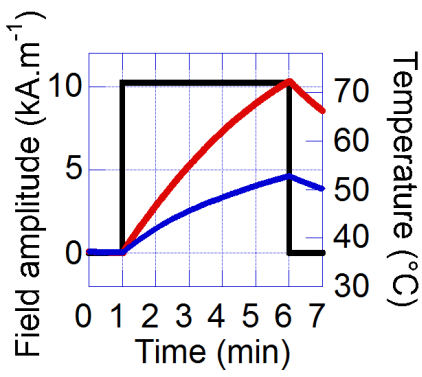

Fig. S3. Temperature increase of IONPs under an alternating magnetic field (AMF) at $755 \mathrm{kHz}, 10.2 \mathrm{kA} \cdot \mathrm{m}^{-1}$, applied during $5 \mathrm{~min}$, for multicore (red line) and monocore IONPs (blue line), dispersed at $3 \mathrm{~g} \cdot \mathrm{L}^{-1}$ iron oxide in dilute $\mathrm{HNO}_{3} \mathrm{pH}$. The SAR values were calculated from the initial slopes of temperature profiles within the first $5 \mathrm{~s}$ of AMF application. The sample tubes ( $1 \mathrm{~mL}$ ) were placed in an expanded polystyrene holder for thermal insulation (yet imperfect).

(B)<smiles>O=C(CCCN1C(=O)C=CC1=O)ON1C(=O)CCC1=O</smiles>

(A)<smiles>NCCP(=O)(O)O</smiles>

$\frac{0.2 \text { equiv. GMBS in DMSO }}{\mathrm{PB} \text { buffer, } \mathrm{pH}=7}$ ice bath, $24 \mathrm{~h}$<smiles>O=C(CCCN1C(=O)C=CC1=O)NCCP(=O)(O)O</smiles><smiles>COCCOCCS</smiles>

(E)<smiles>COCCOCCSC1CC(=O)N(CCCC(=O)NCCP(=O)(O)O)C1=O</smiles>

Fig. S4. Chemical modification of PEG with AEP and GMBS in order to couple it to phosphonate anchor group (AEP-GMBS-PEG).

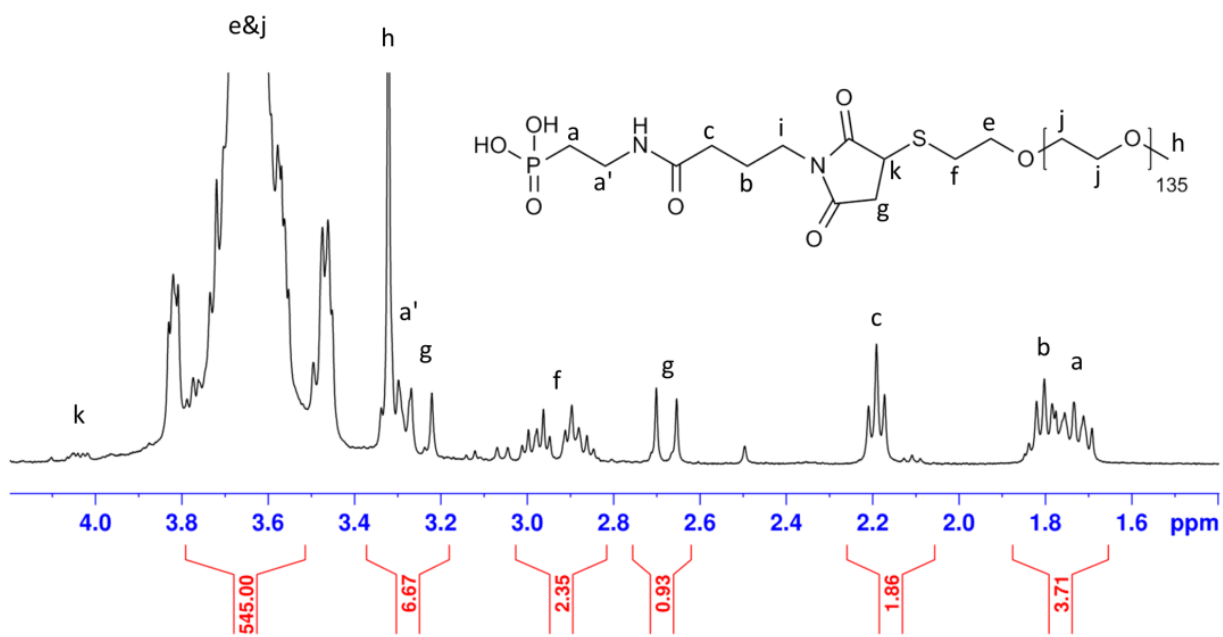

Fig. S5. ${ }^{1} \mathrm{H}$ NMR spectrum of the chemically modified AEP-GMBS-PEG in water. The peak from PEG served as a reference for the integration of other peaks, with its value fixed at 545 protons according to the average molar mass $M_{n}=6,000 \mathrm{~g} \cdot \mathrm{mol}^{-1}$ stated by the supplier, leading to an average degree of polymerization $D P=135$. The reaction was quantitative for the first reaction step leading to the formation of an amide bond between GMBS and AEP. The thiol-maleimide Michael addition of PEG and AEP-GMBS had a chemical yield of $80 \%$, possibly due to the parasitic formation of disulfides during the reaction. 


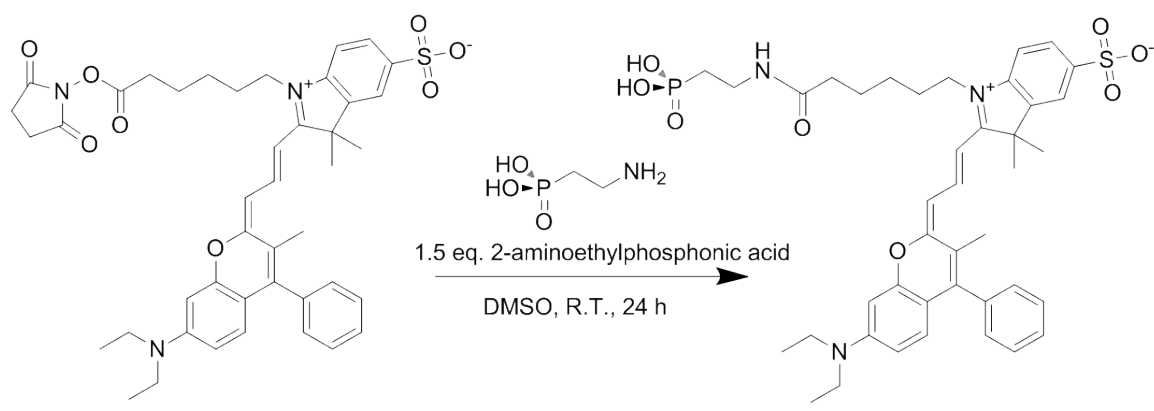

Fig. S6. Synthesis scheme of the chemical modification of the DY700-NHS fluorophore to add a phosphonic acid end-group.

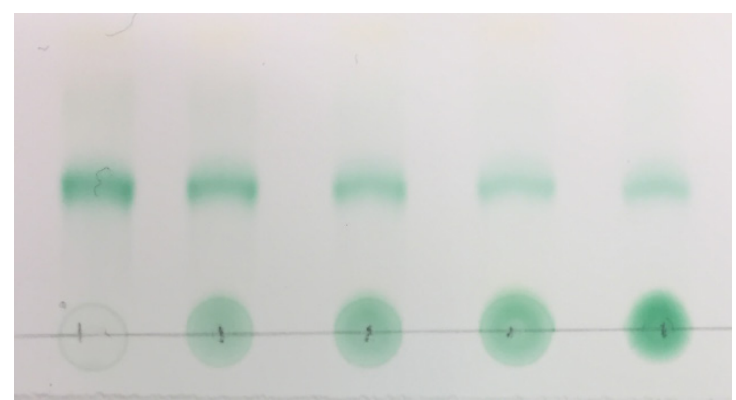

Fig. S7. $1 \mu \mathrm{L}$ of reaction medium was spotted at regular time intervals (from left to right: $0,1,2.5,4.5$, and $22 \mathrm{~h}$ ) on a thin layer chromatography (TLC) plate. The compounds were eluted using a 95:5 mixture of DCM and MeOH. Top spots correspond to DY700-NHS ester, bottom spot correspond to AEP-DY700 which phosphonate anchor group bound to the surface of silica plate. This binding effect on a metal oxide was later advantageously used to tag the surface of IONPs.

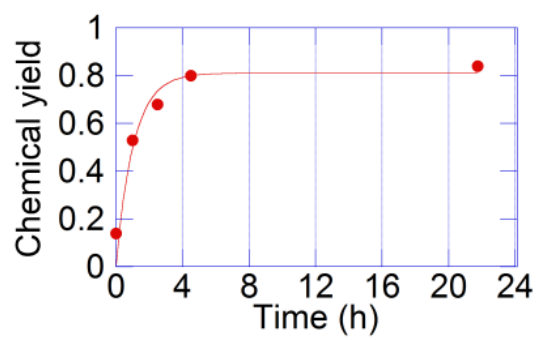

Fig. S8. Ratios of AEP-DY700/DY700 as a function of time evaluated by TLC. For this experiment, it was hypothesized that the green intensity (absorbance) was proportional to the quantity of molecules. The intensities were quantified using the gel analysis plugin in ImageJ. The green coloration in the corresponding DY700-NHS ester (top) and AEP-DY700 (bottom) areas where integrated using the ImageJ software (Fiji version https://fiji.sc/) to calculate a yield.

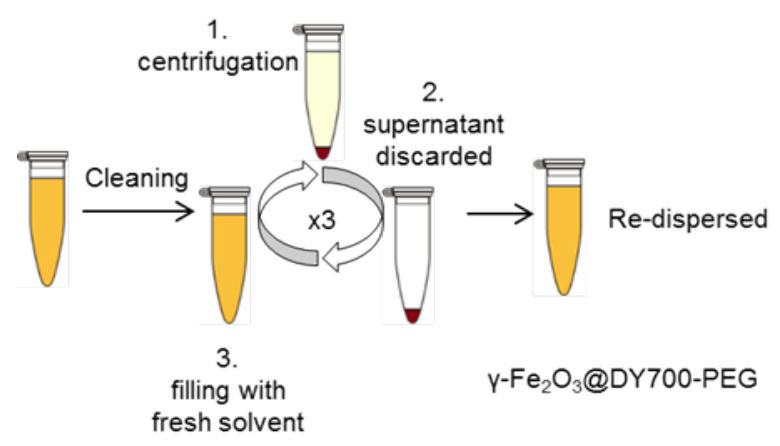

Fig. S9. Scheme of the centrifugation-redispersion process used to purify the IONPs from the excess of AEP-DY700 and AEP-GMBS-PEG.

$\left(18,000 \mathrm{~g}, 1 \mathrm{~h}\right.$ at $25^{\circ} \mathrm{C}, 30 \mathrm{~min}$ at $1^{\circ} \mathrm{C}$ to increase viscosity and avoid pellet dispersion before removing supernatant). 
a)

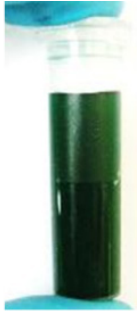

b)

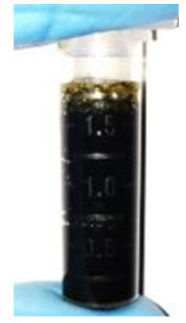

c)

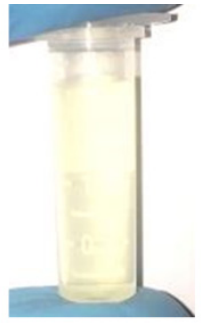

Fig. S10. a) AEP-DY700 in solution. b) Colour of the solution after addition of the IONPs and AEP-GMBS-PEG. c) Colour of the supernatant after the first round of centrifugation, showing that most of the AEP-DY700 was grafted onto the IONPS.

a)

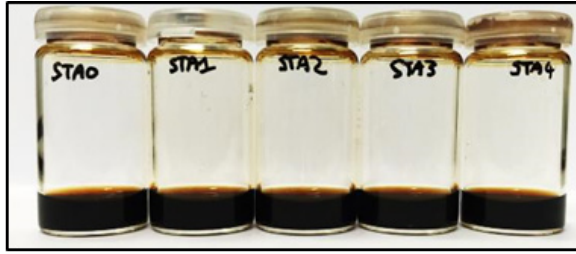

b)
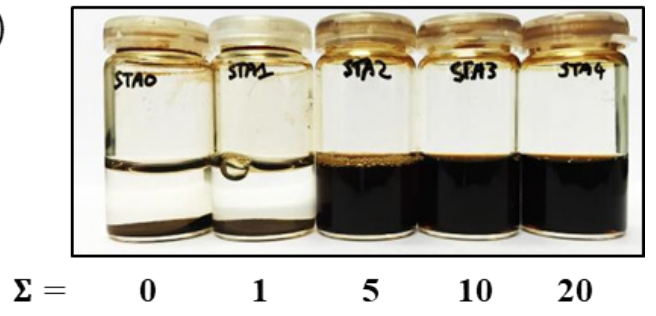

Fig. S11. Stability test of 5 samples conjugated with AEP-GMBS-PEG at various reduced tethered densities $\Sigma$ a) before and $\mathbf{b}$ ) after addition of Tris leading to a neutralization of the acidic solutions.

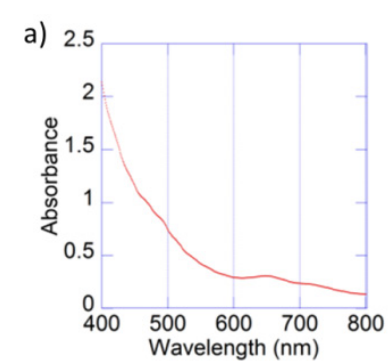

c)

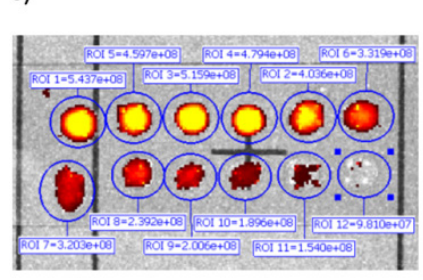

b)
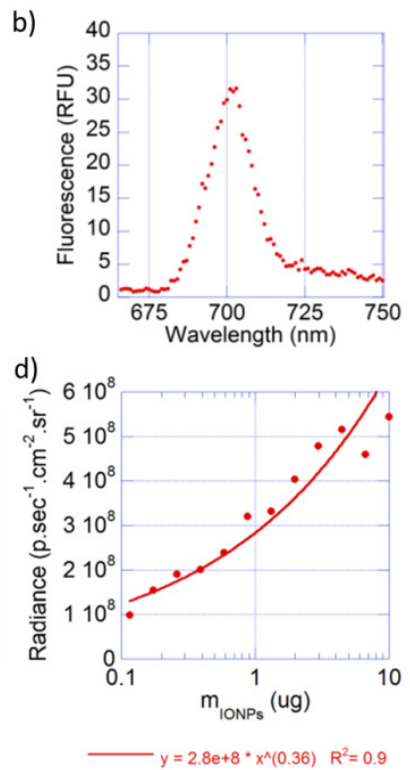

Fig. S12. a) Absorbance of multicore IONPs grafted with AEP-DY700 and AEP-GMBS-PEG. b) Fluorescence of the IONPs. c) Fluorescence of the IONPs as observed with the Lumina instrument. d) Standard calibration curve of the fluorescence intensity integrated in the circular ROIs as a function of the quantity of IONPs in each well, fitted by a power law of exponent 0.36 . 
a)

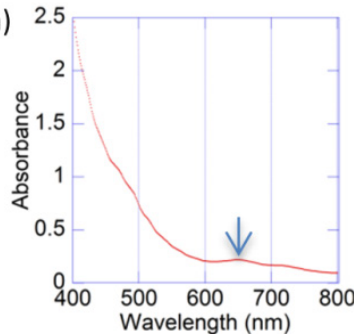

c)

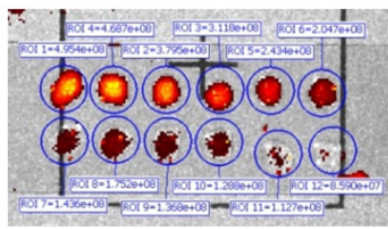

b)

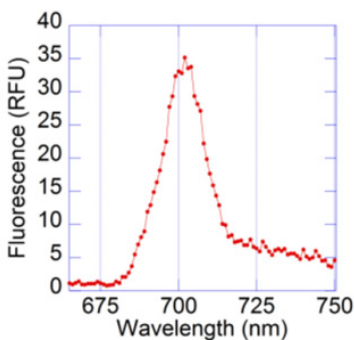

d)

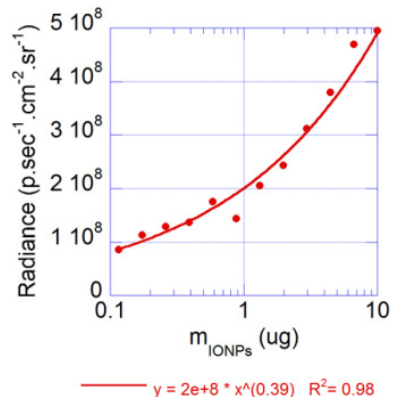

Fig. S13. a) Absorbance of monocore IONPs grafted with AEP-DY700 and AEP-GMBS-PEG. b) Fluorescence of the IONPs. c) Fluorescence of the IONPs as observed with the Lumina instrument. d) Standard calibration curve of the fluorescence intensity integrated in the circular ROIs as a function of the quantity of IONPs in each well, fitted by a power law of exponent 0.39.
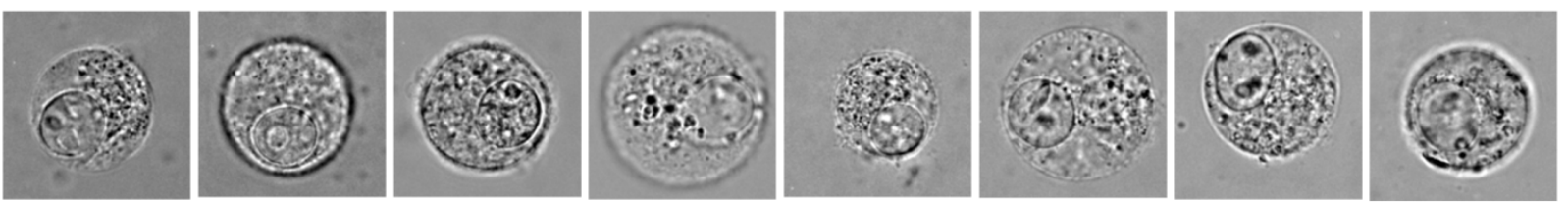

Fig. S14 Cells incubated with monocore IONPs observed by bright field microscopy showing some internal "granularity".
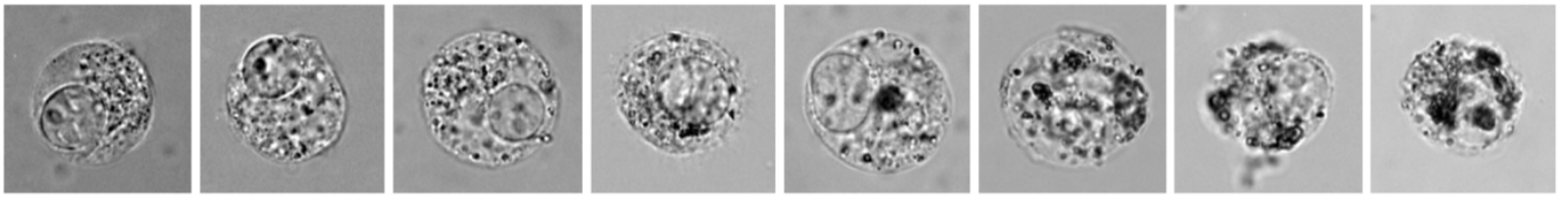

Fig. S15. Cells incubated with multicore IONPs observed by bright field microscopy, with even more dark spots inside (yet cells are perfectly alive). 


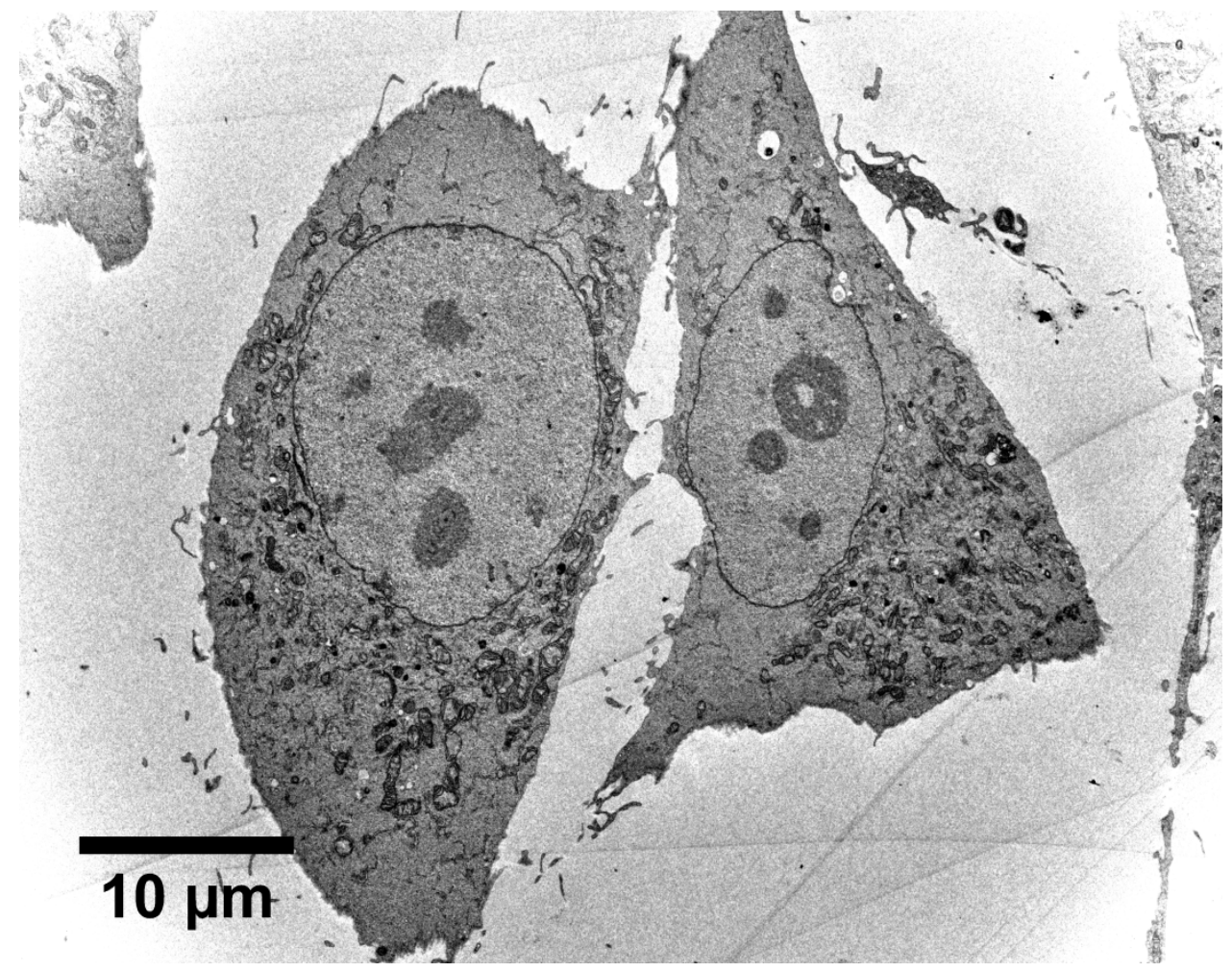

Fig. S16. U87 cells observed by TEM at low magnification, showing their microstructure.

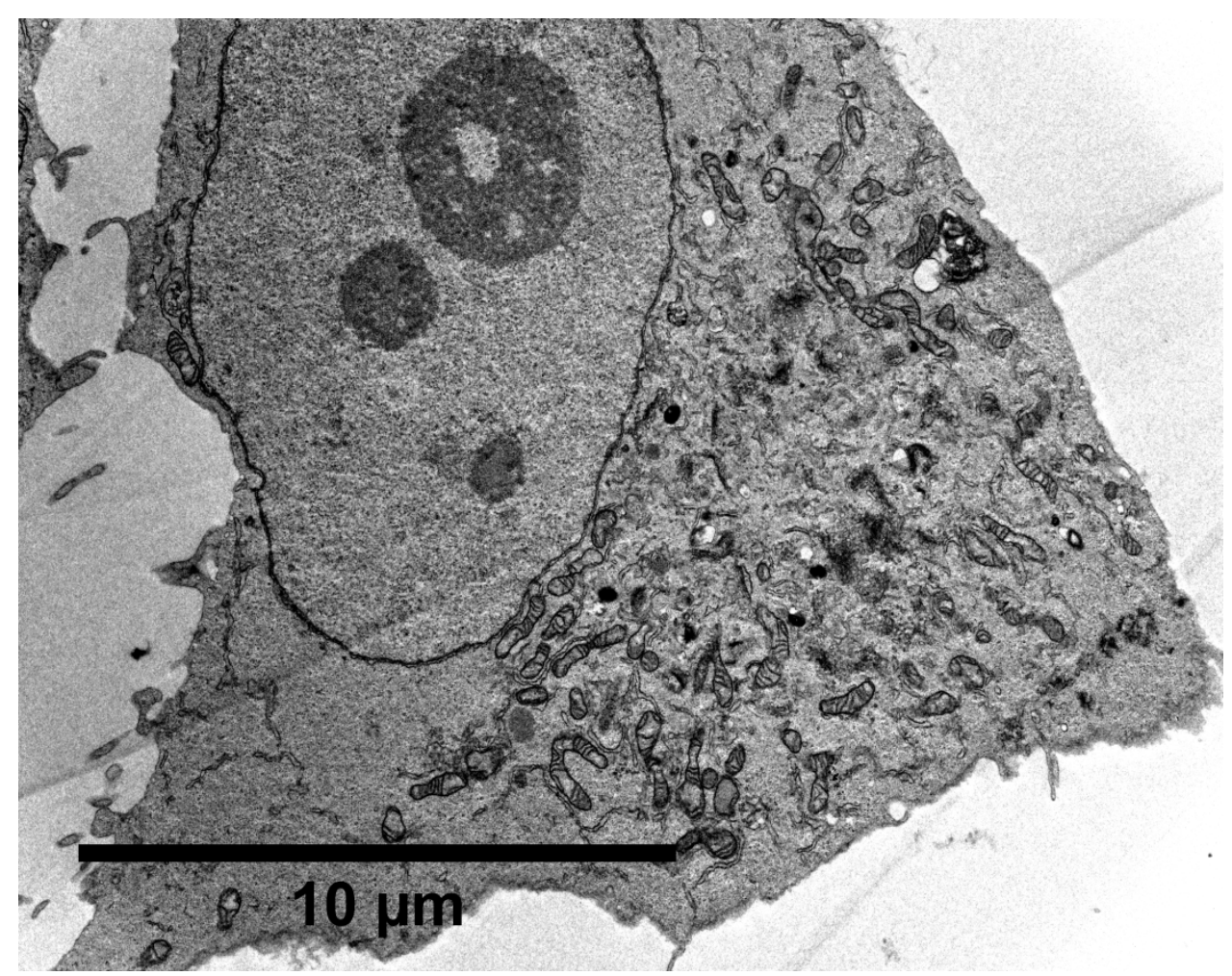

Fig. S17. U87 cells observed by TEM 


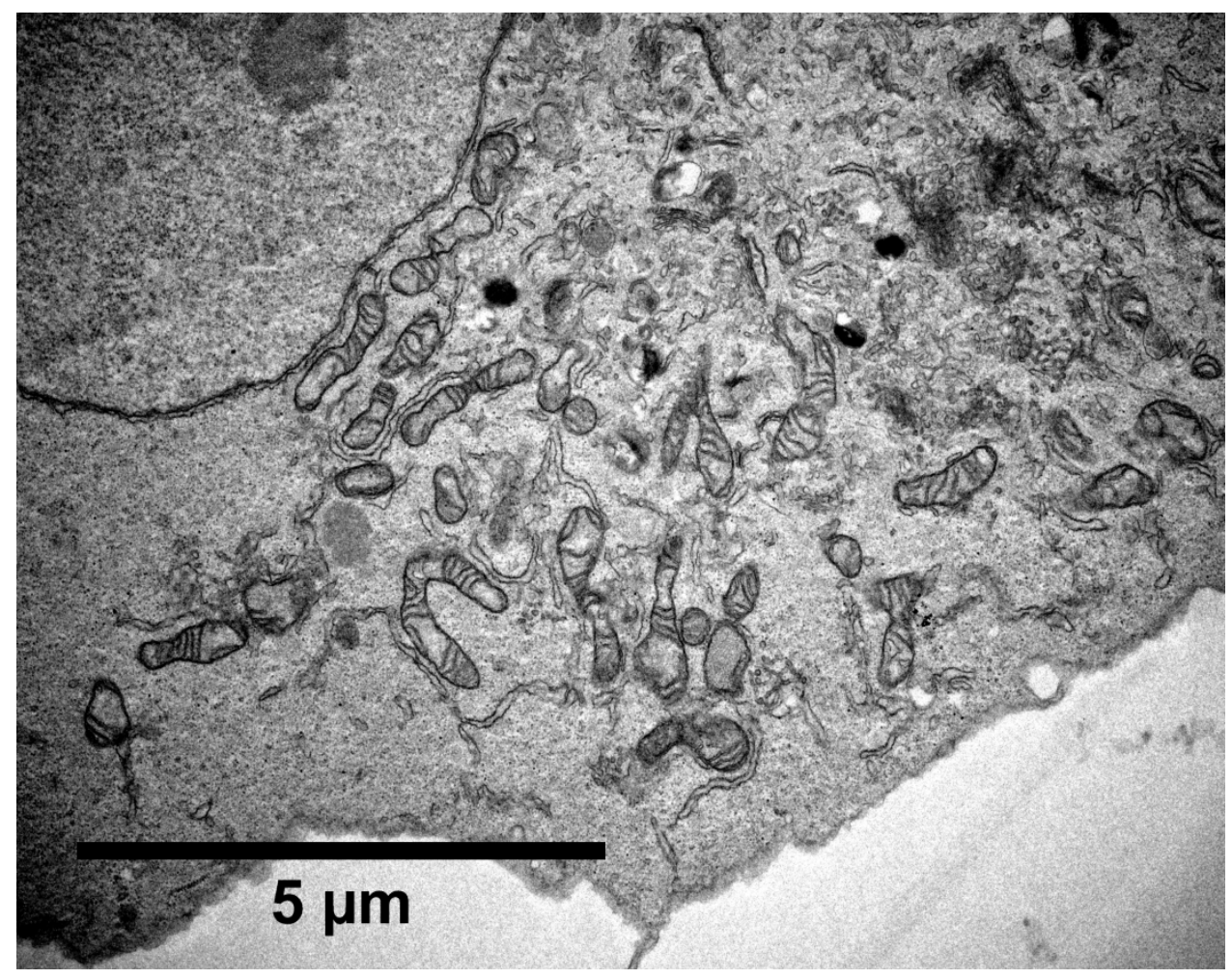

Fig. S18. U87 cells observed by TEM: Zoom on mitochondria

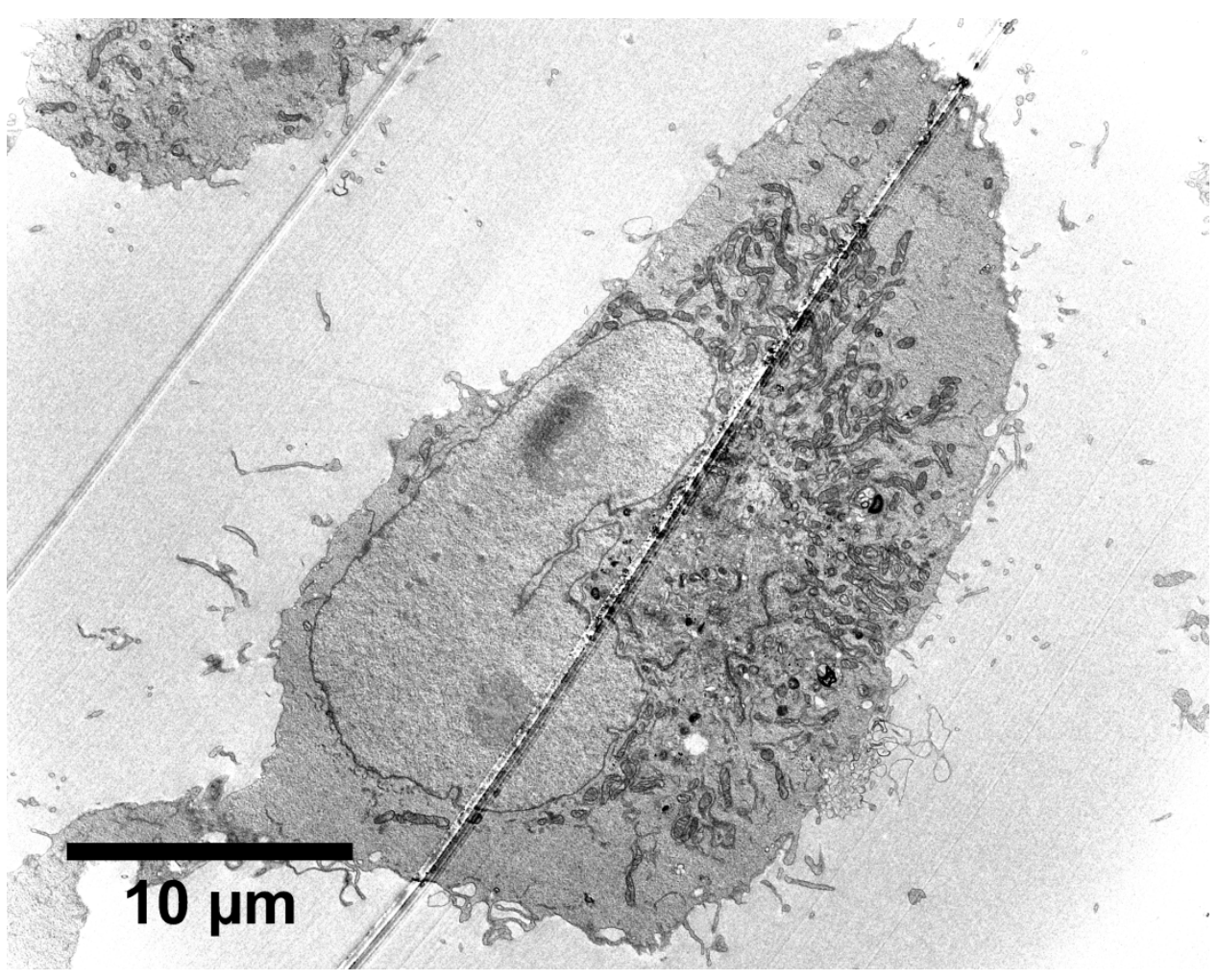

Fig. S19. U87 cells incubated with monocore IONPs observed by TEM 


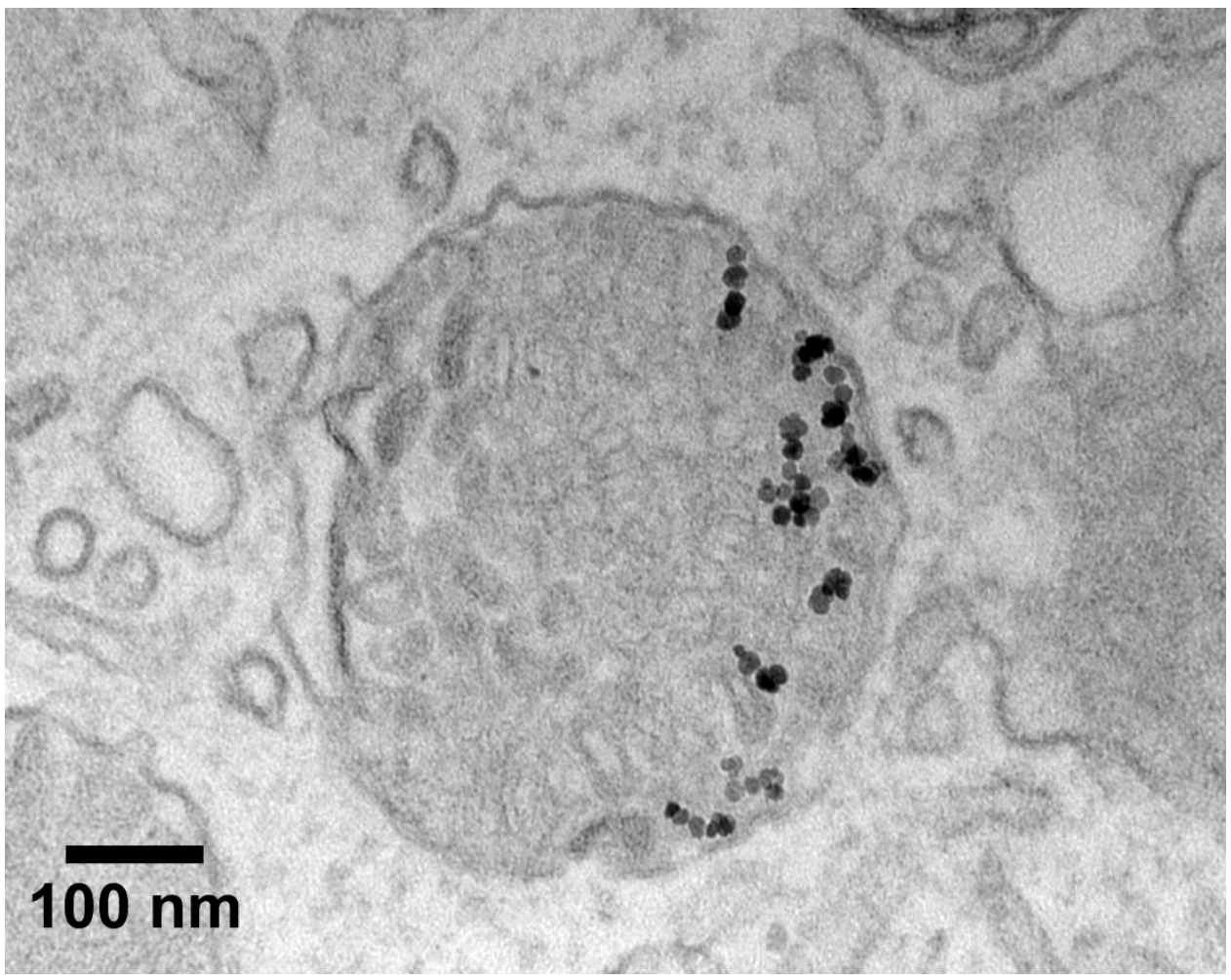

Fig. S20. U87 cells incubated with monocore IONPs observed by TEM: Zoom on a magnetic endosome

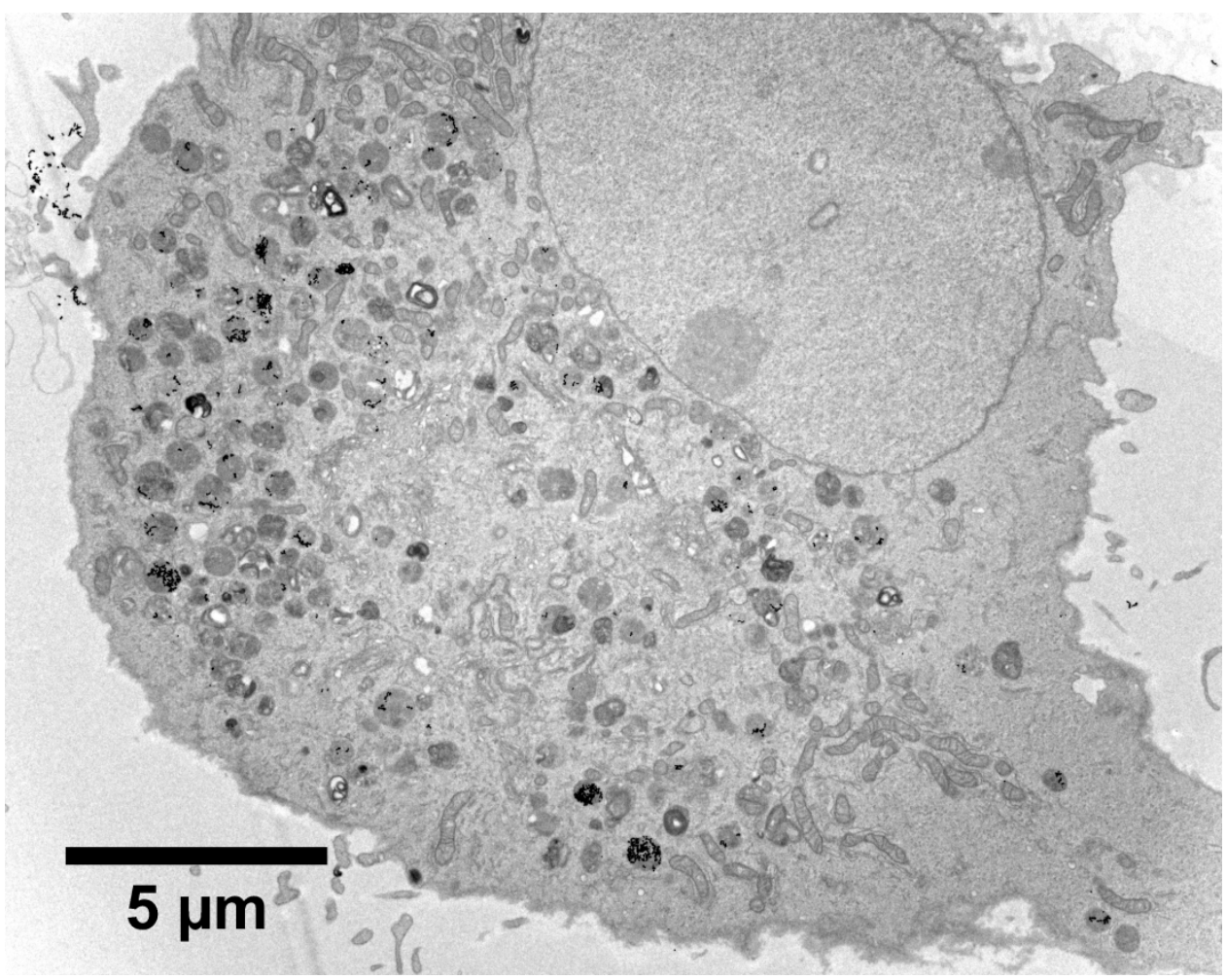

Fig. S21. U87 cells incubated with multicore IONPs observed by TEM 


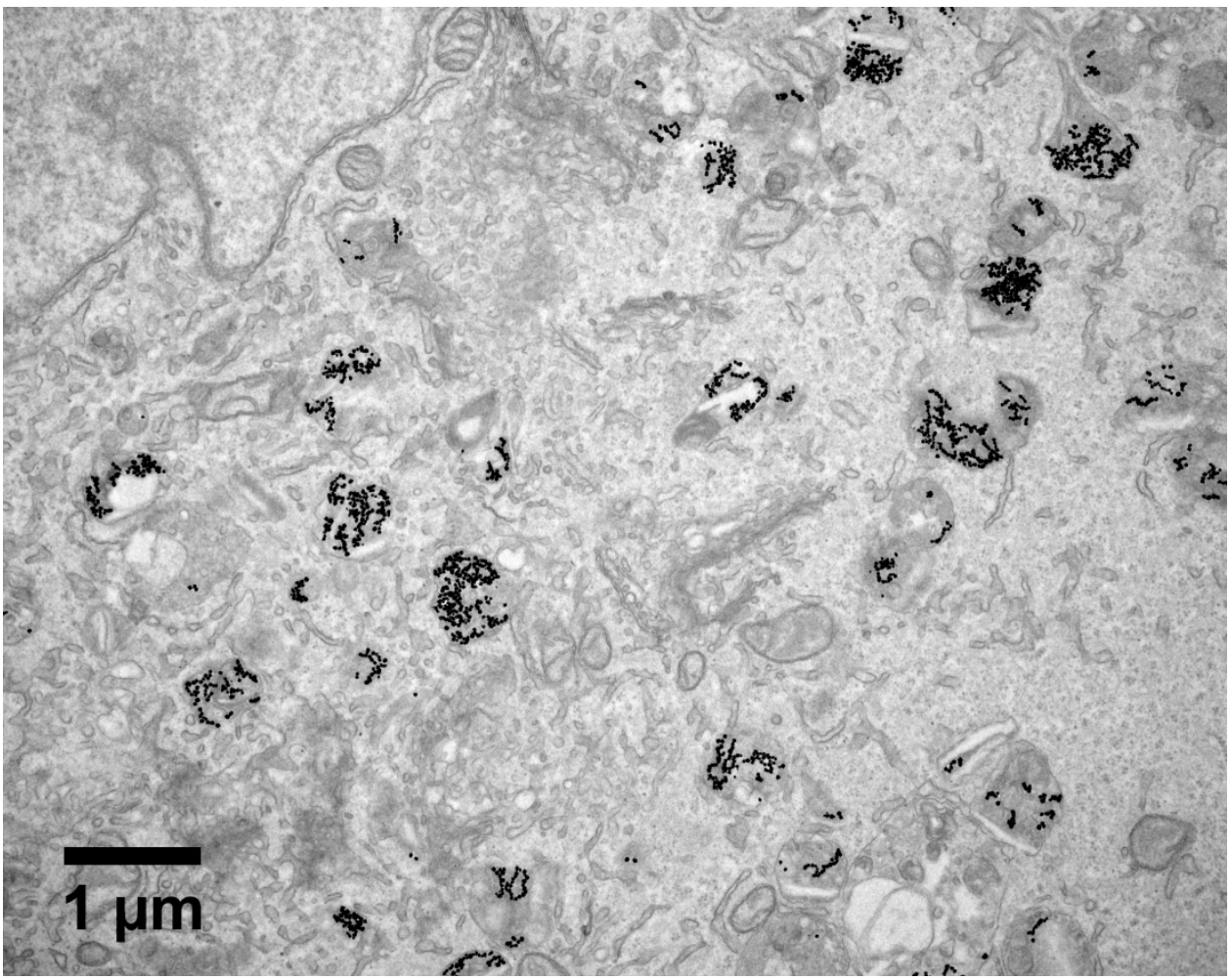

Fig. S22. U87 cells incubated with multicore IONPs observed by TEM

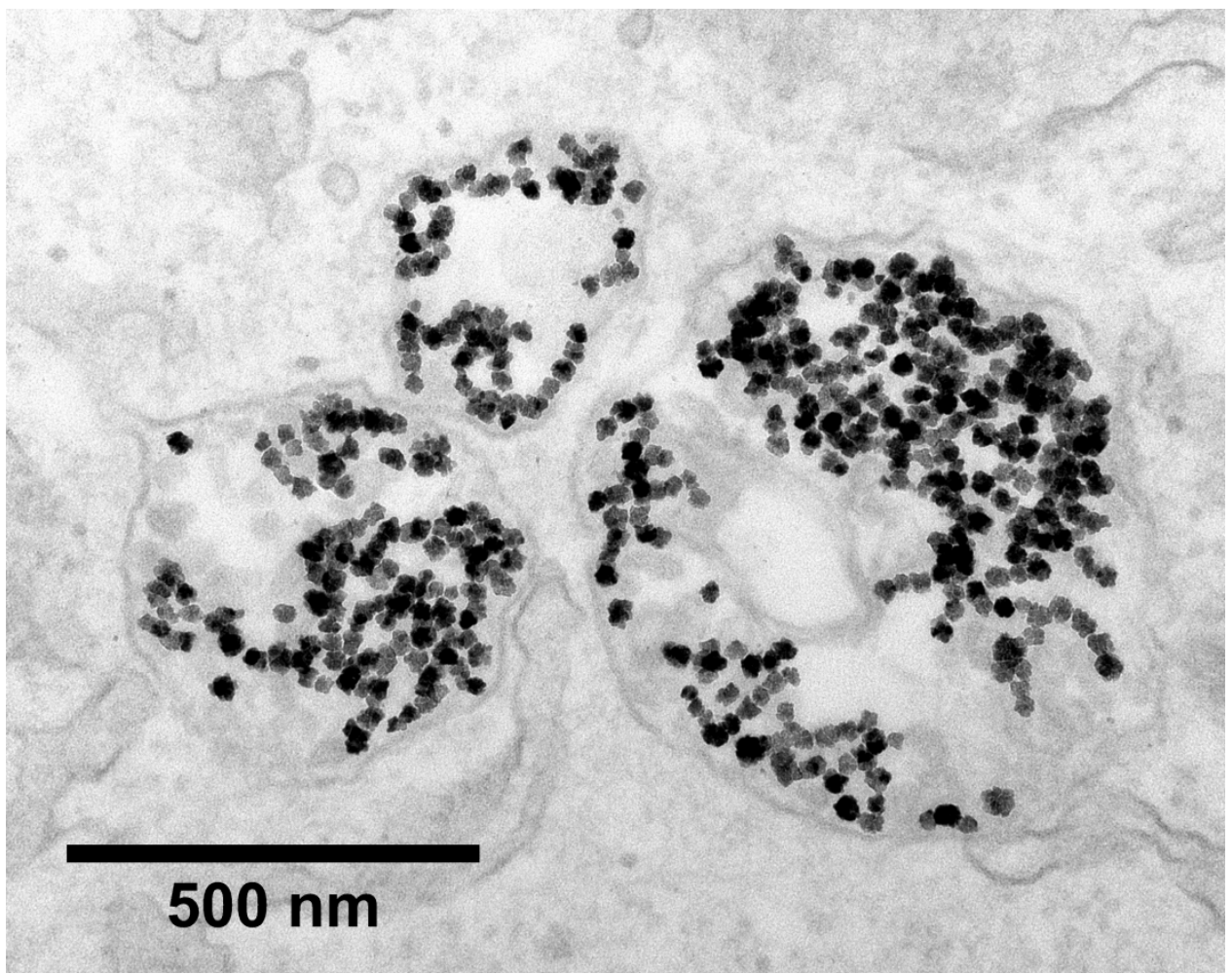

Fig. S23. U87 cells incubated with multicore IONPs observed by TEM: Zoom at high magnification of lysosomes heavily loaded in IONPS. 

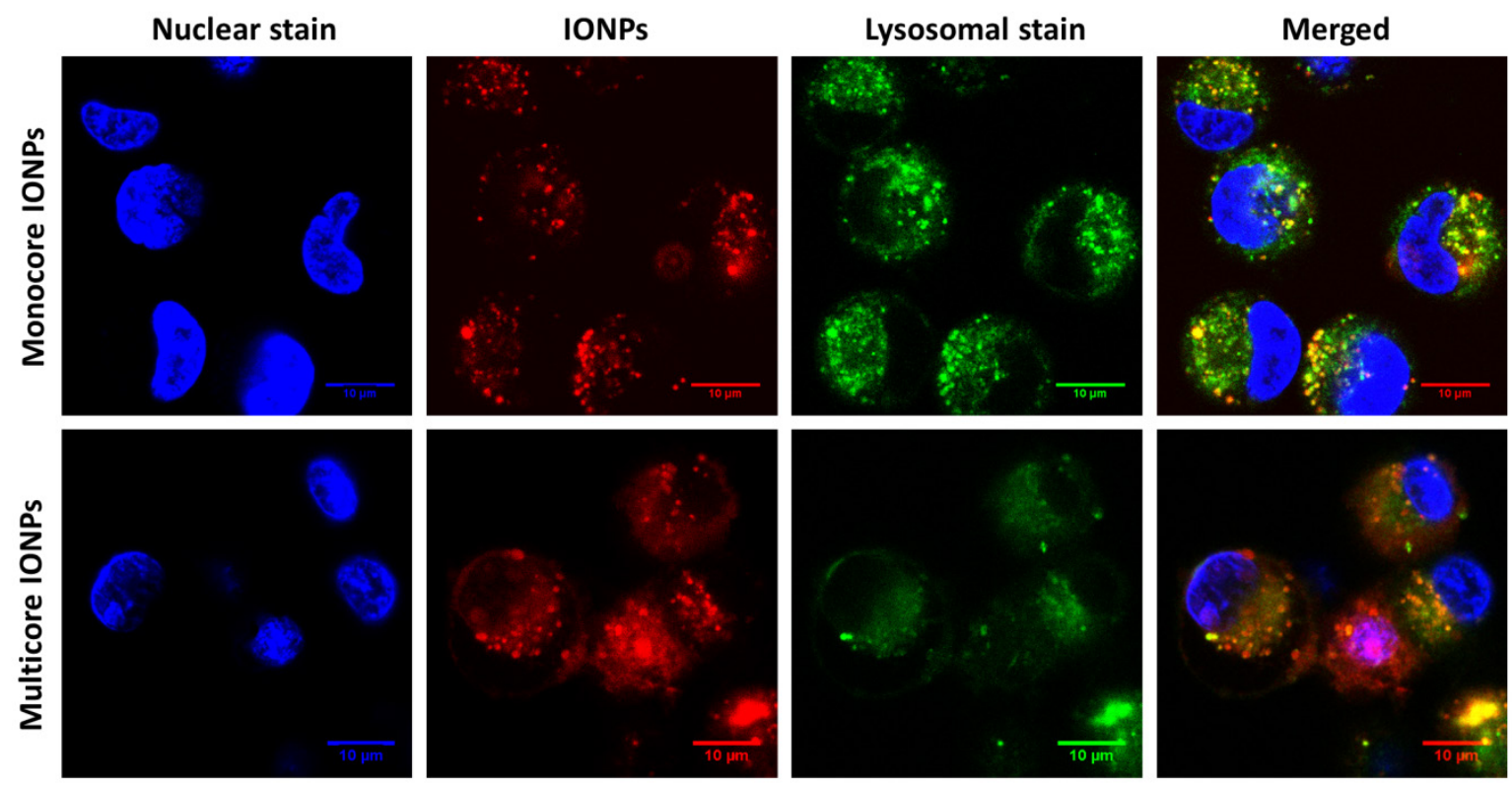

Fig. S24. Fluorescence confocal microscopy of U87 glioblastoma cells incubated with monocore or multicore IONPs. The colocalization between the red fluorescence of the IONPs (labelled with DY700 dye) and the green fluorescence of the lysosomes (labelled with Lysotracker ${ }^{\mathrm{TM}}$ dye) was quantified using the co-localization plugin of ImageJ software

(https://imagej.net/Colocalization - hardware setup and image acquisition), yielding Pearson correlation and overlap coefficients of respectively 0.20 and 0.92 for the monocore IONPs and 0.35 and 0.94 for the multicore IONPs, showing in both case a very high co-occurrence (overlapping) yet low correlation, presumably because the green emission of Lysotracker ${ }^{\mathrm{TM}}$ is absorbed by iron oxide (thus the two signals are not proportional when the two emitting dye molecules are located within the same pixel of the image). 